\title{
Resonance Scattering Effects in Wet Hail Observed with a Dual-X-Band-Frequency, Dual-Polarization Doppler on Wheels Radar ${ }^{\mathscr{O}}$
}

\author{
MATTHEW R. KUMJIAN AND YvetTe P. RichaRdSON \\ Department of Meteorology and Atmospheric Science, The Pennsylvania State University, University Park, Pennsylvania \\ Traeger Meyer, Karen A. Kosiba, And Joshua Wurman \\ Center for Severe Weather Research, Boulder, Colorado
}

(Manuscript received 24 December 2017, in final form 4 September 2018)

\begin{abstract}
Two of the "Doppler on Wheels" facility radars (DOW6 and DOW7) have been upgraded to dualpolarization capabilities and operate at two closely spaced X-band frequencies. For particles with sizes that are large relative to the wavelength, resonance scattering effects may lead to differences in the backscattered radiation between these two frequencies. This study investigates the utility of dual-frequency, dual-polarization DOW radars for hail detection and sizing. T-matrix scattering calculations at the two X-band DOW7 frequencies reveal that dual-frequency differences in the radar reflectivity factors at horizontal polarization $\left(\Delta_{\lambda} Z_{H}\right)$ and differential reflectivities $\left(\Delta_{\lambda} Z_{\mathrm{DR}}\right)$ exist for hailstones, whereas negligible differences exist for raindrops. These differences are enhanced for wet or melting hailstones. Further, these dual-frequency differences may be positive or negative, thereby defining four distinct quadrants in the $\Delta_{\lambda} Z_{H}-\Delta_{\lambda} Z_{\mathrm{DR}}$ parameter space that occur for narrow bands of hail sizes. DOW7 data from two hail-bearing storms are analyzed: one produced only small hail, and the other produced severe hail up to $\sim 3.8 \mathrm{~cm}$ in diameter. The analysis reveals dual-frequency signals that are consistent with the scattering calculations for those sizes, including consistent changes in the signatures below the melting layer in the first storm as hailstones acquire more liquid meltwater and a shift in the $\Delta_{\lambda} Z_{H}-\Delta_{\lambda} Z_{\mathrm{DR}}$ parameter space over time as the second storm grew upscale and hail sizes decreased. Implications for further applications and suggestions about closely spaced dual-frequency observations at other wavelengths are discussed.
\end{abstract}

\section{Introduction and background}

Radar meteorologists have known for decades that the equivalent radar reflectivity factor (hereafter reflectivity) of electromagnetically large particles will differ as a function of radar wavelength. For example, Atlas and Ludlam (1961) provide calculations of backscattering cross sections of dry and wet hailstones at multiple wavelengths, revealing large differences between them. These differences in backscattering cross section arise owing to what are often called resonance scattering effects. To understand resonance scattering, consider the conceptual model of Bohren and Huffman

\footnotetext{
Supplemental information related to this paper is available at the Journals Online website: https://doi.org/10.1175/JAMC-D-170362.s1.

Corresponding author: Dr. Matthew Kumjian, kumjian@psu.edu
}

(1983), wherein a particle may be decomposed into a large number of tiny scattering elements that behave as dipole oscillators when illuminated by a radar wave. In the limit of particles with a very small diameter $D$ relative to the wavelength of incident radiation, the particle's tiny scattering elements are illuminated by a relatively uniform electric field at any instant in time. Because this electric field is oscillating, the tiny scattering elements likewise begin oscillating, and do so in phase with one another. The total radiation scattered by the particle thus resembles that of a single dipole oscillator and is well described by the Rayleigh approximation. The backscattering cross section for such particles increases as $D^{6}$. For particles that are sufficiently large relative to the wavelength such that the incident electric field at an instant in time varies substantially across the particle, the tiny scattering elements oscillate out of phase with one another. This will lead to constructive or destructive interference of radiation produced by each scattering element, collectively 
referred to as "resonance" scattering effects. Such resonance scattering effects result in a total scattered radiation pattern not well described by the Rayleigh approximation. The backscattering cross section of such large particles exhibits a complicated dependence on $D$ that features large peaks and dips, especially for solid spherical or spheroidal particles whose larger mass and symmetry lead to significant constructive and destructive interference of the scattered radiation. Such peaks and dips are characteristic of what is often and ill-advisedly (see Bohren 1992) called the Mie-scattering regime after Mie (1908), although in strict terms Mie's theory only applies to homogeneous dielectric spheres.

The differing response of different-frequency radiation to large particles like hailstones is the fundamental premise behind many traditional dual-frequency radar techniques. Typically, a long wavelength is chosen such that scattering is well described by the Rayleigh approximation, and a short wavelength is chosen to be in the resonance scattering regime for the particles of interest. The difference in reflectivity $(\mathrm{dB})$ between the two wavelengths is taken, sometimes called a dual-wavelength ratio (DWR). For example, Eccles and Atlas (1973) and Carbone et al. (1973) proposed and demonstrated the use of S- and X-band (wavelengths of $\sim 10$ and $\sim 3 \mathrm{~cm}$, respectively) measurements for hail detection. Jameson and Srivastava (1978) and Jameson and Heymsfield (1980) also performed scattering calculations and presented observations of S-X-band reflectivity differences in hail. Dual-frequency techniques also have been augmented with use of radar polarimetry: Bringi et al. (1986), Tuttle et al. (1989), and Herzegh and Jameson (1992) combined S-band differential reflectivity $Z_{\mathrm{DR}}$ measurements with S-X reflectivity differences in studies of hailstorms, and Vivekanandan et al. (1990) extended this analysis to the S, C, and X bands. More recently, Picca and Ryzhkov (2012) investigated a hailstorm using S- and C-band $(\sim 5 \mathrm{~cm})$ dual-polarization radars, finding substantial differences between the two frequencies in the reflectivity and other polarimetric radar variables. Junyent and Chandrasekar (2016) made use of attenuation differences between signals at $\mathrm{S}$ - and X-band frequencies to better characterize DWR signals associated with hail. The dualfrequency approach to hail detection has been extended to include different frequency pairs for airborne radar (Louf et al. 2014). Given that attenuation typically is larger at the higher frequency, proper attenuation correction is necessary for using such techniques (e.g., Tuttle and Rinehart 1983).

Other applications of multifrequency approaches have emerged. For example, Hogan et al. (2005) retrieved liquid water content in stratocumulus clouds with $\mathrm{K}_{a^{-}}(\sim 1 \mathrm{~cm})$ and $\mathrm{W}$-band $(\sim 3 \mathrm{~mm})$ radar and presented a detailed treatment of various error sources in applications of the DWR technique. Gaussiat et al. (2003) used S-, $\mathrm{K}_{a^{-}}$, and $\mathrm{W}$-band radar to retrieve cloud and ice water contents in mixed-phase clouds. Similarly, Kneifel et al. (2011) also explored using three radar frequencies $\left(\mathrm{K}_{u}\right.$, or $2 \mathrm{~cm} ; \mathrm{K}_{a}$; and $\mathrm{W}$ bands) to identify different types of snow particles. Using electromagnetic scattering calculations, they found that different particle types (e.g., pristine crystals, aggregates) reside in different parts of the parameter space defined by the two DWRs. Follow-up observations (Kneifel et al. 2015) generally support this approach. Ellis and Vivekanandan (2010) used differences in water vapor attenuation between $\mathrm{S}$ and $\mathrm{K}_{a}$ bands to retrieve low-level relative humidity profiles. Using three closely spaced K-band frequencies (with $\sim 20 \%$ bandwidth), Meneghini et al. (2005) presented the feasibility of simultaneously obtaining vertical profiles of water vapor density and rain total number concentration and median mass diameter. Williams (2012) exploited different sensitivities to Rayleigh and Bragg scattering with 50- and 920-MHz radar wind profilers to retrieve air vertical velocities. Using zenith-pointing $\mathrm{K}_{a}$ - and W-band Doppler spectra in rain, Tridon et al. (2013) separated the effects of differential attenuation and resonance scattering, which can be used for drop size distribution retrievals (e.g., Tridon et al. 2017). Large pieces of debris found in tornadoes also create an observable dual-frequency response, as shown by Bodine et al. (2014). Thus, use of different frequency bands is a powerful approach to remotely sensing clouds and precipitation, as well as nonmeteorological scatterers.

Melnikov et al. (2010) presented a variation on the traditional dual-wavelength technique in which two closely spaced S-band frequencies are used. They compared data from two dual-polarization WSR-88D sets collected during a severe hailstorm. The two radars [in the Norman, Oklahoma, area (KOUN) and (KCRI)] are in close proximity $(243 \mathrm{~m})$ and operate at S-band frequencies differing by only $290 \mathrm{MHz}$. Melnikov et al. $(2010,2014)$ found differences in $Z_{\mathrm{DR}}$ of several decibels between the two S-band frequencies, which they attributed to wet, nonspherical hailstones with diameters in excess of $4-5 \mathrm{~cm}$. Such large differences for closely spaced frequencies require resonance scattering: large oscillations in the backscattering cross section or other radar variables as a function of particle size that are characteristic of the "Mie" regime have peaks and dips that are slightly offset between the two frequencies.

Thus, like the traditional dual-wavelength approach, using closely spaced frequencies also exploits resonance scattering for particles that are large relative to the radar wavelength. An advantage of using closely spaced frequencies is that attenuation differences between the two 
are not expected to be large. Attenuation correction is challenging in melting hail (e.g., Snyder et al. 2010; Borowska et al. 2011; Ryzhkov et al. 2013b), leading to difficulties in isolating the resonance scattering response when using widely separated frequencies like S-X, S-C, and so on. However, a limitation of the Melnikov et al. (2010, 2014) analyses and numerous other dual-wavelength hail studies referenced above is the use of two different radars: this leads to difficulties in matching beams in time and space, meaning that very often the same population of hydrometeors is not being sampled simultaneously. Rinehart and Tuttle (1982) and Williams and Vivekanandan (2007) found that mismatched beams can cause large errors in the measured DWRs and retrieved quantities. Given the rapid evolution of polarimetric radar features in severe convective storms (e.g., Kumjian et al. 2010; Houser et al. 2015; Tanamachi and Heinselman 2016), nonsimultaneous sampling leads to some ambiguity whether the observed signatures are associated with resonance scattering effects or storm evolution. Thus, closely spaced dualfrequency polarimetric radars with matched beams are desirable for isolating resonance scattering effects in hail from differences in attenuation, storm evolution, or other sampling issues.

The newly upgraded dual-X-band-frequency, dualpolarization "Doppler on Wheels" (DOW) radars (DOW6 and DOW7; e.g., Wurman et al. 2012) are capable of such measurements, using a single antenna for both X-band frequencies. The DOW radars' upgrade to two frequencies was performed for two primary reasons. First, the two frequencies are separated by $150 \mathrm{MHz}$, which results in nearly completely independent samples of every radar volume. As a result, the DOWs can scan twice as fast and achieve the same accuracy as a single-frequency system, which is important for sampling rapidly evolving severe storms. Second, the DOWs employ two frequencies in order to implement different polarimetric data collection modes: for example, one frequency may be used to simultaneously transmit horizontally and vertically polarized waves, whereas the other transmits only one polarization and can thus measure the linear depolarization ratio. In this study, for the first time we explore the use of this dual-X-band-frequency, dual-polarization DOW radar data to detect hail and estimate its size. In the next section, we present electromagnetic scattering calculations as a theoretical framework for interpreting the dualwavelength signatures in various types of precipitation that can be used in future studies. Section 3 is an analysis of DOW7 observations that demonstrate the dual-wavelength technique. The observations come from a hailstorm in Pennsylvania collected during an education and outreach project, as well as a severe storm during the Plains Elevated Convection at Night
TABLE 1. DOW7 specifications.

\begin{tabular}{ll}
\hline \multicolumn{1}{c}{ Attribute } & \multicolumn{1}{c}{ Value } \\
\hline Low frequency & $9.35 \mathrm{GHz}$ \\
High frequency & $9.50 \mathrm{GHz}$ \\
Transmitter type & Magnetron \\
Peak power & $0.5 \mathrm{MW}$ \\
Antenna type & Parabolic \\
Antenna diameter & $2.44 \mathrm{~m}$ \\
Low-frequency beamwidth & $0.92^{\circ}$ \\
High-frequency beamwidth & $0.91^{\circ}$ \\
Polarization & Simultaneous $H$ and $V$ \\
\hline
\end{tabular}

field project (PECAN; Geerts et al. 2017). A discussion of the results and summary of the main conclusions is presented in section 4 .

\section{Electromagnetic scattering calculations}

To explore the expected dual-frequency response to various hydrometeors, we employ the T-matrix method (e.g., Bringi and Seliga 1977a,b; Mishchenko 2000) to compute hydrometeor scattering properties at the two DOW7 X-band frequencies of 9.35 and $9.50 \mathrm{GHz}$ (see Table 1). These calculations should be considered applicable to the DOW7 frequencies only. For these calculations, hydrometeors are treated as one- or two-layer uniformly filled oblate spheroids with minor axis (symmetry axis) $a$ and major axis $b$. Raindrops are taken as $0^{\circ} \mathrm{C}$ pure liquid spheroids, with their axis ratio varying as a function of size following Brandes et al. (2002), as corrected in their corrigendum. The raindrop sizes we consider range from 0.05 to $7.95 \mathrm{~mm}$ in $0.1-\mathrm{mm}$ increments. Dry hailstones are treated as oblate ice spheroids with density $\rho_{\text {ice }}=917 \mathrm{~kg} \mathrm{~m}^{-3}$, ranging in size from 1 to $50 \mathrm{~mm}$ in $0.1-\mathrm{mm}$ increments. For wet/melting hailstones, we use two-layer spheroids with an inner ice core and an outer shell of liquid water. For "wet" hailstones, we consider a 0.5 -mm-thick liquid coating on particles with diameters from 1 to $50 \mathrm{~mm}$ in $0.1-\mathrm{mm}$ increments. These are meant to represent wet hailstones aloft undergoing wet growth. For "melting" hailstones, we use ice-core diameters from 0.1 to $40 \mathrm{~mm}$ in $0.1-\mathrm{mm}$ increments. The stones are coated by liquid according to their maximum retainable meltwater, which varies as a function of size following Rasmussen and Heymsfield (1987) and Ryzhkov et al. (2013a) as

$$
m_{w, \max }=m_{8}+0.139\left(m_{i}+m_{w, \text { soak }}\right),
$$

where $m_{8}=2.68 \times 10^{-4} \mathrm{~kg}$ is the mass of an $8-\mathrm{mm}$ raindrop, $m_{i}$ is the mass of the ice core, and $m_{w \text {,soak }}$ is the mass of liquid soaked within the particle. Because we assume the ice cores are solid ice, $m_{w \text {,soak }}=0$ here. 
Laboratory studies by Rasmussen et al. (1984) reveal that the liquid meltwater tends to accumulate at the equator of the particle in a "torus." As such, the total particle axis ratio $\gamma \equiv a / b$ can be different from the ice-core axis ratio $\gamma_{i} \equiv a_{i} / b_{i}$ (Fig. 1a). Herein, we assumed $\gamma_{i}=0.7$. The total particle axis ratio is computed from the inner-core axis ratio and maximum liquid water fraction as follows. We assume that the total particle minor axis $a=a_{i}+\delta a$, where $\delta a=$ $0.5 \mathrm{~mm}$. The total particle major axis is $b=b_{i}+\delta b$, where $\delta b$ is computed using the inner core and $\delta a$ as constraints and fixing the liquid water coating mass as $m_{w, \max }$ from Eq. (1), resulting in (see the appendix for a detailed derivation)

$$
\delta b=\left[\left(\frac{6 m_{8}}{\pi \rho_{w}}+\frac{C a_{i}^{3}}{\gamma_{i}^{2}}\right) \frac{1}{a_{i}+\delta a}\right]^{1 / 2}-\frac{a_{i}}{\gamma_{i}},
$$

where $\rho_{w}=1000 \mathrm{~kg} \mathrm{~m}^{-3}$ is the bulk density of liquid water and

$$
C=\left(1+0.139 \frac{\rho_{\text {ice }}}{\rho_{w}}\right)=1.1275 .
$$

For small $(<12 \mathrm{~mm})$ hailstones that have large liquid water mass fraction, Eq. (2) results in unrealistically low axis ratios. As such, we define $\gamma_{\min }=0.56$, which is the minimum axis ratio for the largest raindrop considered $(\sim 8 \mathrm{~mm})$. This parameterization is a modification of the one suggested by Ryzhkov et al. (2011) (Fig. 1b) in which melting-hail axis ratios rapidly approach 0.8 with increasing particle size. This modification allows the liquid coating axis ratio to differ from that of the ice core, which is thought to be a more realistic representation of the shape of melting hail (Rasmussen et al. 1984). Additionally, we modify the canting-angle-distribution standard deviation for melting hail $\sigma_{\text {melt }}$ such that it is a function of the difference in total particle axis ratio from that of the inner ice core,

$$
\sigma_{\text {melt }}=\sigma_{\text {dry }}+\frac{\gamma_{i}-\gamma}{\max \left(\gamma_{i}-\gamma\right)}\left(\sigma_{\text {rain }}-\sigma_{\text {dry }}\right),
$$

and varies linearly between that assumed for rain $\left(\sigma_{\text {rain }}=10^{\circ}\right)$ and that assumed for dry hail $\left(\sigma_{\text {dry }}=40^{\circ}\right)$, as shown in Fig. 1c. The idea is that a protruding liquid torus stabilizes the fall behavior of hailstones (Rasmussen et al. 1984). The original Ryzhkov et al. (2011) parameterization similarly varies $\sigma_{\text {melt }}$ linearly between $\sigma_{\text {rain }}$ and $\sigma_{\text {dry }}$, but as a function of liquid water fraction. This leads to a larger dispersion of canting angles for low-axis ratio, highliquid mass fraction particles (Fig. 1c). Note that the equations for computing the radar variables in Ryzhkov et al. (2011) are valid for small $\sigma$, so a more (a)
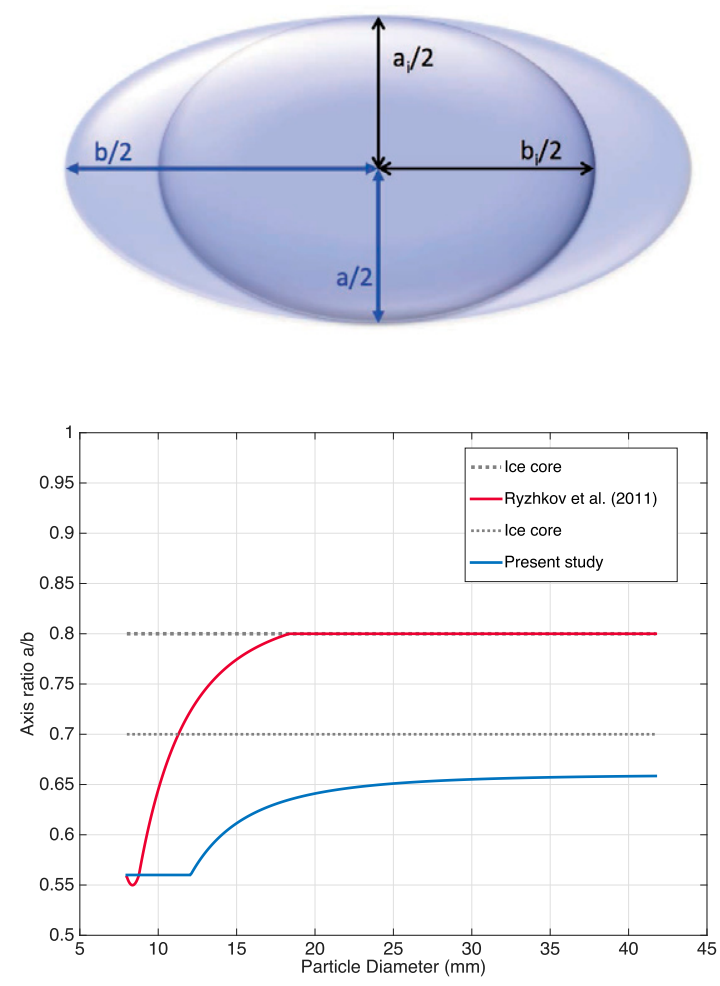

(c)

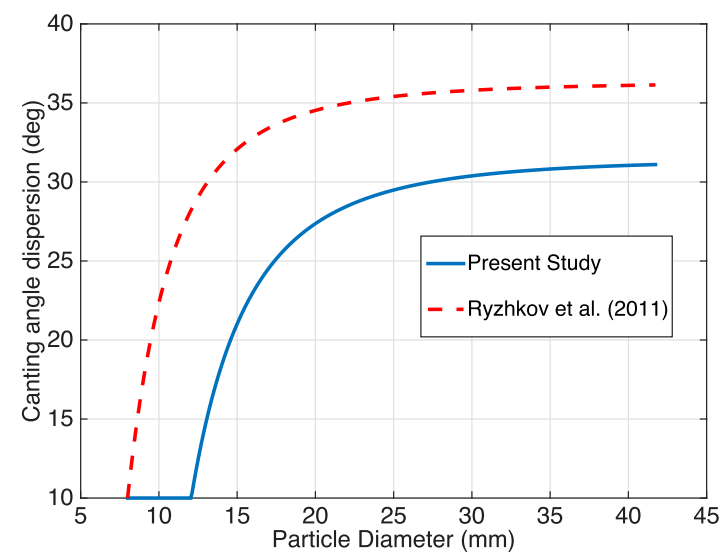

FIG. 1. (a) Schematic illustrating the geometry of spheroids approximating melting hail in our scattering calculations. The inner ice-core axis ratio $a_{i} / b_{i}=0.7$ is different from the total particle axis ratio $a / b$. (b) Comparison of the axis ratio as a function of size in the present study (blue) with the parameterization of Ryzhkov et al. (2011) (red). Axis ratios of the dry ice particles are shown by dotted gray lines. (c) Canting-angle dispersion $\sigma\left(^{\circ}\right)$ as a function of size for the present study (blue) and Ryzhkov et al. (2011) (red).

rigorous treatment (e.g., Melnikov 2017) is required for broad orientation distributions. The use of larger $\sigma$ values here is to achieve the effect of dampening the polarimetric contrasts of drier hail, as was done in Ryzhkov et al. (2011). Tests using more rigorous treatments (Melnikov 2017) did not affect the results. 
These modifications were made 1) to provide more realistic shapes of the liquid coating and inner ice core, which in general may be different, and 2) to address the inability of the Ryzhkov et al. (2011) parameterization to reproduce large $Z_{\mathrm{DR}}$ values often found in observations at $S$ and $X$ bands (e.g., Kumjian 2013a; Snyder et al. 2013). It is clear that there are a number of "tunable" parameters that must be specified for these calculations. Unfortunately, many of these details are highly uncertain; detailed study of hailstone shapes and falling and melting behaviors are needed to better constrain these parameters. The choices made here are based partly on limited experimental data (e.g., Rasmussen et al. 1984) and partly for consistency with previous studies employing such calculations (e.g., Ryzhkov et al. 2011, 2013a,b; Borowska et al. 2011), with changes as described above for improved agreement with polarimetric radar observations in small melting hail. Sensitivity tests were performed and are discussed below where applicable.

The T-matrix calculations provide the backward and forward scattering amplitudes at both X-band frequencies for each particle. Note that these calculations are valid for a $0^{\circ}$ elevation angle. For larger antenna elevation angles, the polarimetric contrasts (including $Z_{\mathrm{DR}}$ and thus $\left.\Delta_{\lambda} Z_{\mathrm{DR}}\right)$ reduce [e.g., see the formulas in Melnikov (2017)]. From these scattering amplitudes, we compute the normalized dual-polarization radar variables following Ryzhkov et al. (2011, 2013a). Here, "normalized" means a monodisperse size distribution of $1 \mathrm{~m}^{-3}$ is assumed for each particle size bin. In this study, we focus on reflectivity factor at horizontal polarization $Z_{H}$ and differential reflectivity $Z_{\mathrm{DR}}$. Differences in these quantities (low frequency minus high frequency) between the two $\mathrm{X}$-band frequencies herein will be denoted as $\Delta_{\lambda} P$, where $P$ is the polarimetric radar variable of interest.

Calculations for $\Delta_{\lambda} Z_{H}$ and $\Delta_{\lambda} Z_{\mathrm{DR}}$ for raindrops are shown in Fig. 2. For the range of realistic raindrop sizes shown, $\Delta_{\lambda} Z_{H}$ and $\Delta_{\lambda} Z_{\mathrm{DR}}$ values do not exceed $0.1-0.2 \mathrm{~dB}$. Such small values are within the expected observational error of the DOW7 radar (see section 3) and thus likely undetectable. Recall that, because the dual-frequency differences in logarithmic units $(\mathrm{dB})$ are ratios in linear units, they are only affected by the shape of the particle size distribution and are unaffected by particle concentration (e.g., Eccles and Atlas 1973). Thus, the dual-frequency values integrated over most particle size distributions will feature lower values than those shown in our calculations, as seen below. Therefore, we can conclude that pure rain is exceedingly unlikely to exhibit measurable $\Delta_{\lambda} Z_{H}$ or $\Delta_{\lambda} Z_{\mathrm{DR}}$ values.

In contrast, the T-matrix calculations for dual-frequency quantities in both dry and wet hail (Fig. 3) reveal greater

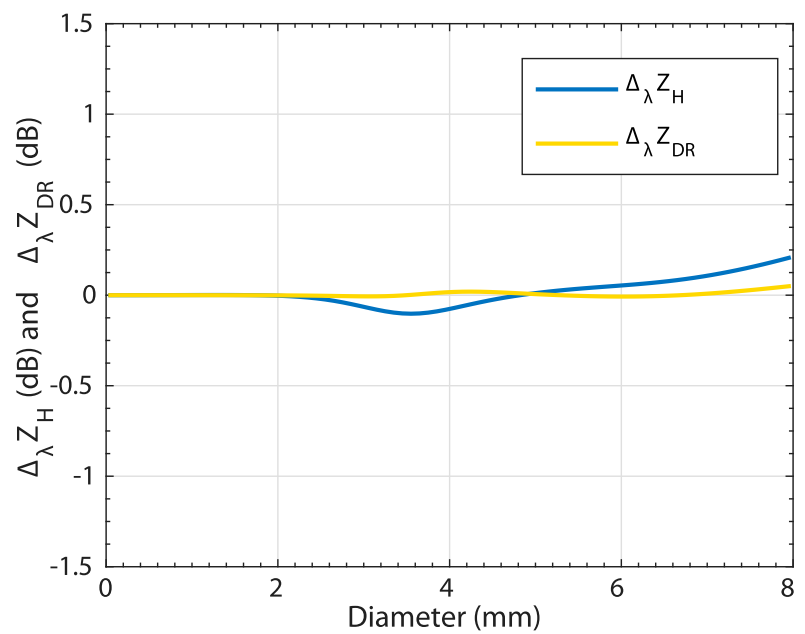

FIG. 2. T-matrix calculations of dual-frequency differences in $Z_{H}\left(\Delta_{\lambda} Z_{H}\right.$; blue $)$ and $Z_{\mathrm{DR}}\left(\Delta_{\lambda} Z_{\mathrm{DR}}\right.$; goldenrod $)$ as a function of size for raindrops.

magnitudes and a complicated dependence on size owing to strong resonance scattering for such large particles. The nonmonotonic behavior of $Z_{H}$ as a function of size (Figs. 3a,c) is a result of such resonance scattering. The maxima and minima are slightly offset for the low- and high-frequency curves, so the difference between these two curves will oscillate from positive to negative values at quasi-regular intervals. This explains the periodic behavior of $\Delta_{\lambda} Z_{H}$ as a function of size (Figs. 3b,d, blue curve). Both dry and wet hailstone $\Delta_{\lambda} Z_{H}$ first cross from positive to negative values at a size of $\sim 15.5 \mathrm{~mm}$. A similar oscillatory behavior is seen in $\Delta_{\lambda} Z_{\mathrm{DR}}$ (Figs. 3b,d, goldenrod curve). In general, the amplitudes of the $\Delta_{\lambda} Z_{H}$ and $\Delta_{\lambda} Z_{\mathrm{DR}}$ maxima and minima are larger for the wet hail than for the dry hail. This is primarily because the addition of liquid water dramatically increases the particle's relative permittivity at the X-band frequencies used herein, increasing its response to radiation. Additionally, the dry hailstones tumble more, which reduces the magnitudes of $Z_{\mathrm{DR}}$ and thus $\Delta_{\lambda} Z_{\mathrm{DR}}$.

Notably, the size dependence is different for $\Delta_{\lambda} Z_{H}$ and $\Delta_{\lambda} Z_{\mathrm{DR}}$. Because $\Delta_{\lambda} Z_{H}$ and $\Delta_{\lambda} Z_{\mathrm{DR}}$ can be positive or negative, this leads to narrow bands of hail sizes characterized by one of four unique combinations of signs for $\Delta_{\lambda} Z_{H}$ and $\Delta_{\lambda} Z_{\mathrm{DR}}$ (e.g., both positive, one positive and one negative, etc.). For example, $\Delta_{\lambda} Z_{H}<0$ and $\Delta_{\lambda} Z_{\mathrm{DR}}>0$ for dry hailstones between 15.5 and $18.2 \mathrm{~mm}$ and for wet hailstones between about 16.7 and $19.6 \mathrm{~mm}$, according to these calculations; this combination does not occur again until sizes $33.4-35.7 \mathrm{~mm}$ for dry hail and 28.6$30.8 \mathrm{~mm}$ for wet hail. Such distinctive fingerprints suggest the possibility of exploiting closely spaced radar 

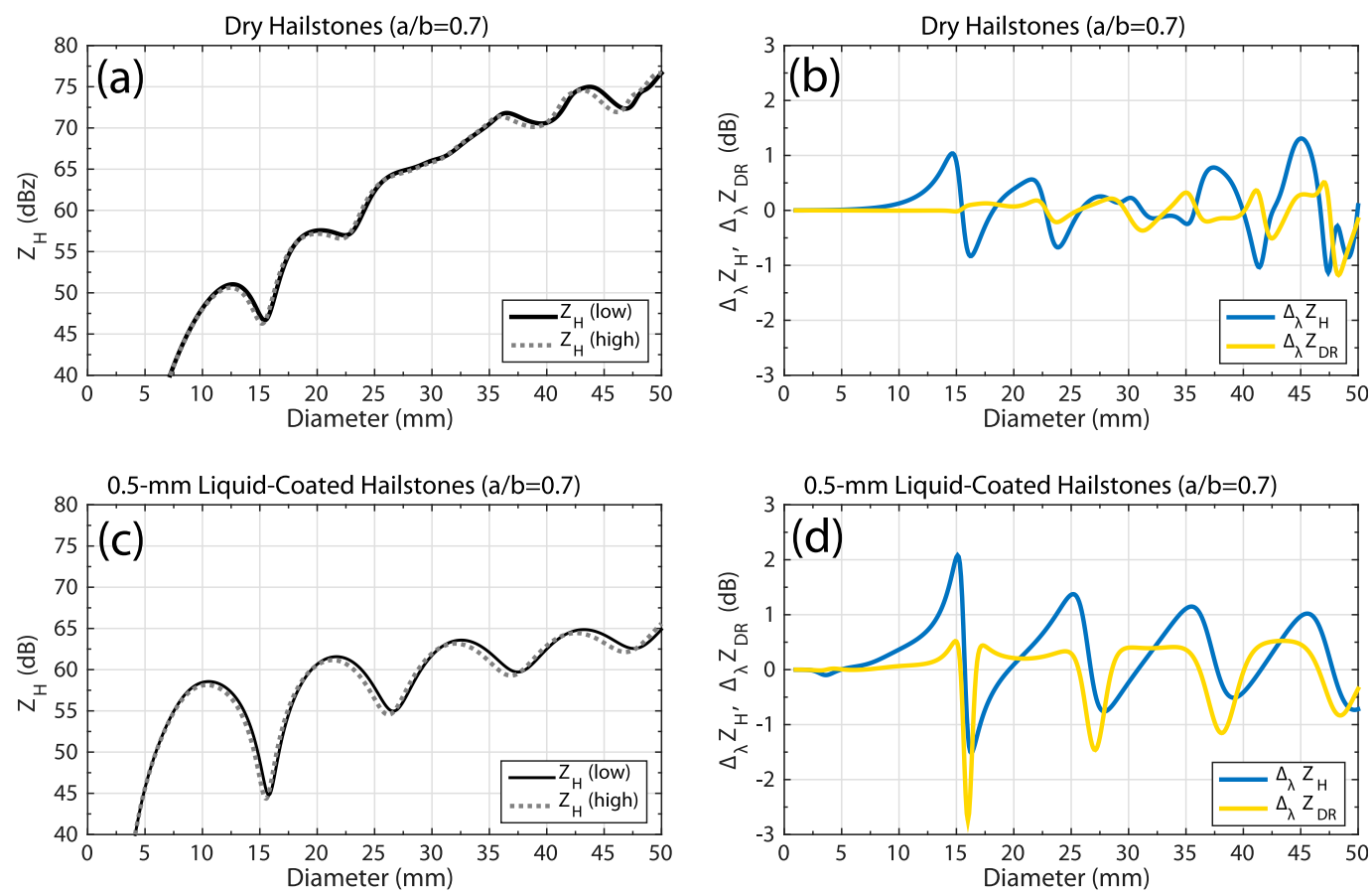

FIG. 3. T-matrix calculations of (a),(c) low-frequency (black solid curve) and high-frequency (dotted gray curve) $Z_{H}$ and (b),(d) dual-frequency differences in $Z_{H}\left(\Delta_{\lambda} Z_{H}\right.$; blue) and $Z_{\mathrm{DR}}\left(\Delta_{\lambda} Z_{\mathrm{DR}}\right.$; goldenrod) as a function of size for (top) dry hailstones with axis ratio $a / b$ equal to 0.7 , where $a$ is the spheroid minor axis and $b$ is the major axis, and (bottom) hailstones with a thin $(0.5 \mathrm{~mm})$ liquid coating.

frequencies for determining hail sizes within limited ranges, although this hinges on better constraint of our models of hailstone shapes, orientations, and melting behaviors.

The hailstones in Fig. 3 are assumed to have an icecore axis ratio of 0.7 ; other axis ratios were tested (see Figs. S1 and S2 in the online supplemental material). The locations of various maxima and minima of the curves shift slightly $(<1$-mm differences) though the overall patterns remain qualitatively similar. As the axis ratio tends toward unity, the $\Delta_{\lambda} Z_{\mathrm{DR}}$ values tend toward $0 \mathrm{~dB}$. Randomly oriented particles produce $Z_{\mathrm{DR}}=0 \mathrm{~dB}$, regardless of their shape, and consequently also produce $\Delta_{\lambda} Z_{\mathrm{DR}}=0 \mathrm{~dB}$. Thus, only oriented, nonspherical particles produce measurable $\Delta_{\lambda} Z_{\mathrm{DR}}$, whereas both spherical and nonspherical particles with any orientation can produce nonzero $\Delta_{\lambda} Z_{H}$. Other sensitivity tests (Figs. S3 and $\mathrm{S} 4$ in the online supplemental material) reveal that $\Delta_{\lambda} Z_{\mathrm{DR}}$ magnitudes increase with decreasing standard deviation of the canting-angle distribution (i.e., more horizontally oriented nonspherical particles produce larger $\Delta_{\lambda} Z_{\mathrm{DR}}$ magnitudes), whereas there is far less sensitivity for $\Delta_{\lambda} Z_{H}$.

Last, we consider melting hailstones by assuming the maximum retained liquid water fraction following Rasmussen and Heymsfield (1987) (Fig. 4). Note that
Fig. 4 shows a smaller range of sizes than Fig. 3. This is to focus on the range of sizes in which the melting parameterization leads to much larger liquid water fractions on the particles than are assumed for the coated spheroids shown in Fig. 3. Although the dependence of $\Delta_{\lambda} Z_{H}$ and $\Delta_{\lambda} Z_{\mathrm{DR}}$ on size for these maximally wet hailstones is similar to those with a thin liquid coating, their amplitudes are larger. Thus, one may expect largeramplitude dual-frequency signatures with increased melting, as well as larger-amplitude signatures in hail below the melting layer relative to those produced by wet stones above.

Over the ranges of sizes considered, dual-frequency differences in specific attenuation $\Delta_{\lambda} A_{H}$ and specific differential attenuation $\Delta_{\lambda} A_{\mathrm{DP}}$ are smaller than $\sim 0.03$ and $\sim 0.02 \mathrm{~dB} \mathrm{~km}^{-1}$ in magnitude, respectively, for a $1 \mathrm{~m}^{-3}$ monodispersed distribution of particles (not shown). The maximum magnitudes occur for very large $(>5-\mathrm{mm}$ diameter) raindrops and small $(<12 \mathrm{~mm})$ melting hailstones. Unlike $\Delta_{\lambda} Z_{H}$ and $\Delta_{\lambda} Z_{\mathrm{DR}}, \Delta_{\lambda} A_{H}$ and $\Delta_{\lambda} A_{\mathrm{DP}}$ do depend on hydrometeor concentration. Given such small values for individual particles, however, we do not expect significant differences in attenuation or differential attenuation between the two frequencies unless a large concentration of large raindrops and/or small melting hailstones is present. 


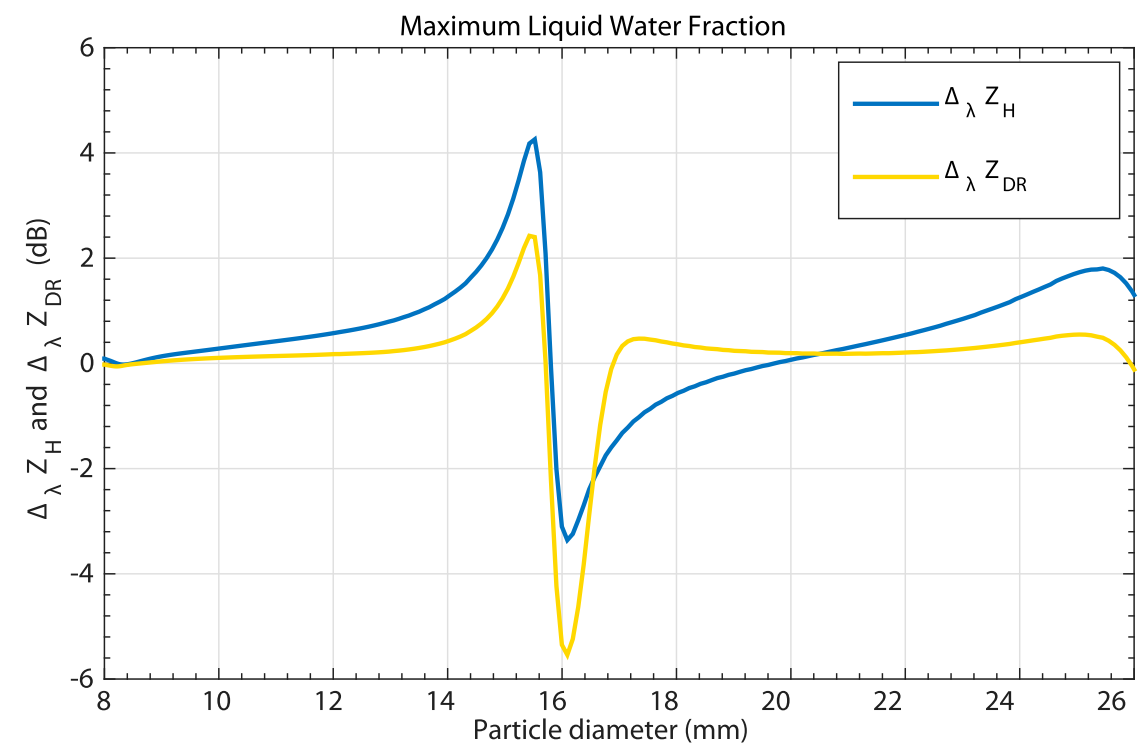

FIG. 4. T-matrix calculations of dual-frequency differences in $Z_{H}\left(\Delta_{\lambda} Z_{H}\right.$; blue) and $Z_{\mathrm{DR}}$ $\left(\Delta_{\lambda} Z_{\mathrm{DR}}\right.$; goldenrod) as a function of size for melting hailstones (i.e., those with their maximum retainable liquid water mass fraction). Note that the axis ranges differ from those in Fig. 3.

Of course, in storms, hailstones are likely to be distributed across a range of sizes, and not monodispersed as has thus far been shown in the scattering calculations. Thus, particle size distributions (PSDs) should be considered to better emulate what may be observed in practice. Unfortunately, hail PSDs are highly uncertain, so a range of different PSDs and PSD shapes are considered here. The idea is to obtain a sense of how different PSD shapes may affect the ability to observe these dual-frequency differences in real storms. Clearly, however, this uncertainty is a limitation of this type of analysis; improved observations of hail PSDs are critically needed.

First, we consider three-parameter gamma PSDs (e.g., Willis 1984), which can have their intercept, slope, and shape parameters varied. Only the slope and shape parameters affect $\Delta_{\lambda} Z_{H}$ and $\Delta_{\lambda} Z_{\mathrm{DR}}$. Further, we use guidance from Ulbrich and Atlas (1982), who find that the average of the product of the slope parameter and maximum diameter $\Lambda \times D_{\max }$ is 7.9 , and $90 \%$ of observed hail PSDs have $\Lambda \times D_{\max }>5$.0. Figures 5a and 5b show $\Delta_{\lambda} Z_{H}$ and $\Delta_{\lambda} Z_{\mathrm{DR}}$ as a function of $D_{\max }$ and $\Lambda$ for PSDs with shape parameter $\mu=0$ (i.e., exponential PSDs). Interestingly, the $\Delta_{\lambda} Z_{H}$ values are always positive for these exponential PSDs, which demonstrates that averaging over a broad size distribution minimizes the influence of deep but narrow dips and peaks seen in the monodisperse particles calculations. Increasing the $\Lambda$ tends to diminish the magnitudes of $\Delta_{\lambda} Z_{H}$ and $\Delta_{\lambda} Z_{\mathrm{DR}}$ because steeper PSD slopes result in far lower concentrations of larger stones (which produce the resonance scattering) relative to the smaller particles. Shallower PSDs allow the particles producing the resonance scattering to dominate the backscattered signal and, consequently, allow for the dual-frequency signals to emerge. The fluctuations in $\Delta_{\lambda} Z_{H}$ and $\Delta_{\lambda} Z_{\mathrm{DR}}$ with increasing $D_{\max }$ reflect the resonance peaks and dips as progressively larger stones are included in the sampling volume (cf. Fig. 4). Overall, the $\Delta_{\lambda} Z_{H}$ and $\Delta_{\lambda} Z_{\mathrm{DR}}$ magnitudes are small for these PSDs: $\Delta_{\lambda} Z_{H}$ ranges from 0.2 to $0.5 \mathrm{~dB}$, whereas $\Delta_{\lambda} Z_{\mathrm{DR}}$ ranges from -0.05 to $0.09 \mathrm{~dB}$. As discussed in the next section, it is unlikely that such small values could be reliably observed by typical radar systems. Last, we see that most of the high-magnitude $\Delta_{\lambda} Z_{H}$ and $\Delta_{\lambda} Z_{\mathrm{DR}}$ values are below the $\Lambda \times D_{\max }=5.0$ (dotted) curve. Because $\Lambda$ is proportional to $D_{0}^{-1}$ (where $D_{0}$ is the median diameter), a smaller $\Lambda \times D_{\max }$ indicates a smaller difference between $D_{\max }$ and $D_{0}$ (i.e., for a given $\Lambda$, the distribution contains a smaller range of sizes than reported by Ulbrich and Atlas). Although not shown here, we also performed calculations for a variety of $\mu$ values. Increasing $\mu$ narrows the distribution and thus allows for larger magnitudes of $\Delta_{\lambda} Z_{H}$ and $\Delta_{\lambda} Z_{\mathrm{DR}}$. For example, for PSDs with $\mu=10, \Delta_{\lambda} Z_{H}$ varies between -0.5 and $1.1 \mathrm{~dB}$, and $\Delta_{\lambda} Z_{\mathrm{DR}}$ varies from -0.8 to $0.2 \mathrm{~dB}$.

We also considered Gaussian functions characterized by a mean diameter and standard deviation (which describes the size distribution width). Figures $5 \mathrm{c}$ and $5 \mathrm{~d}$ show $\Delta_{\lambda} Z_{H}$ and $\Delta_{\lambda} Z_{\mathrm{DR}}$ as a function of mean diameter 

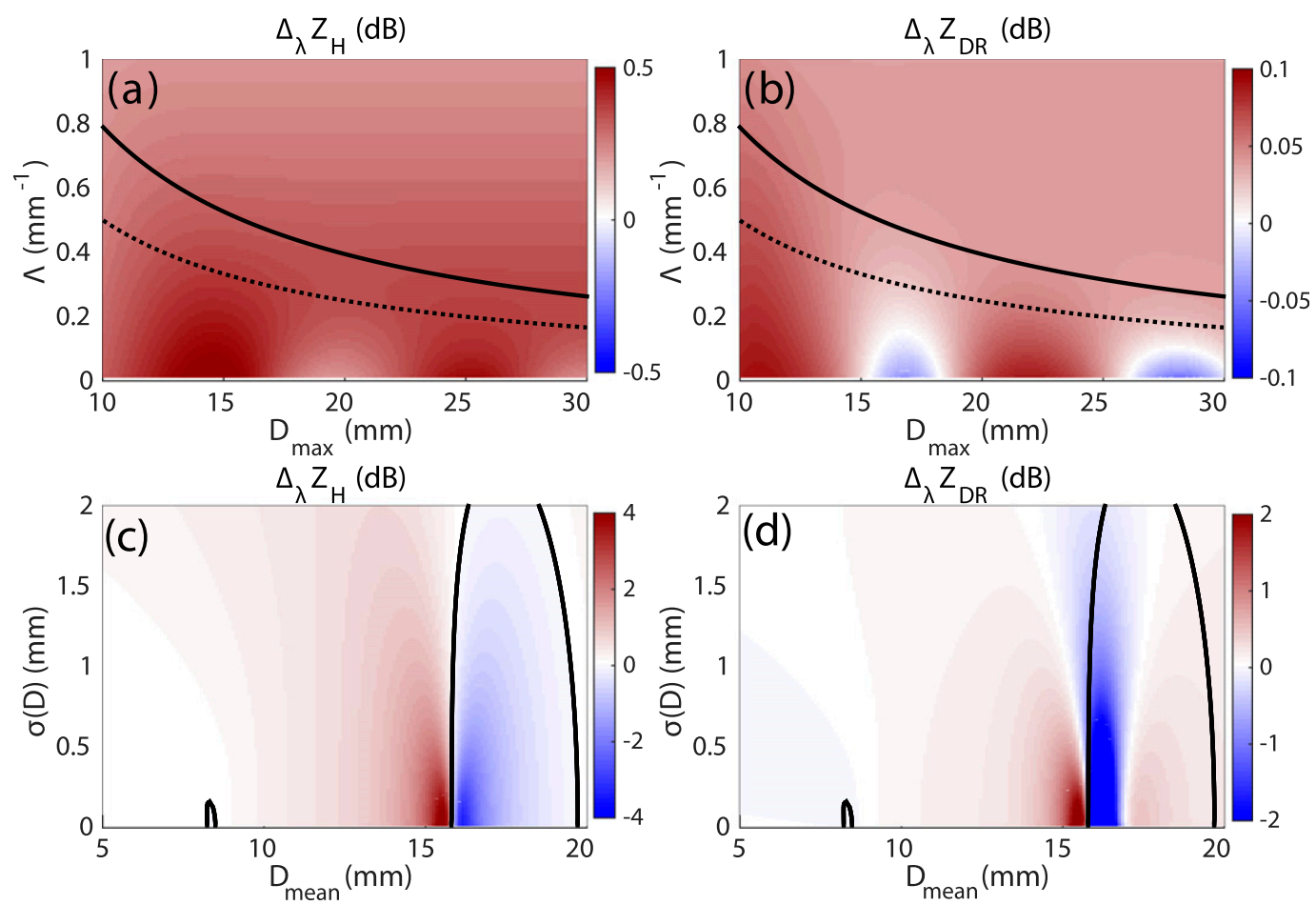

FIG. 5. T-matrix calculations of melting-hail particle size distributions for (left) $\Delta_{\lambda} Z_{H}$ and (right) $\Delta_{\lambda} Z_{\mathrm{DR}}$ (dB, shaded) (a),(b) as a function of exponential size distribution slope parameter $\Lambda$ and maximum diameter $D_{\max }$ (the overlaid solid and dotted lines represent $\Lambda \times D_{\max }=7.9$ and 5.0, respectively) and (c),(d) for Gaussian size distributions as a function of mean diameter $D_{\text {mean }}$ and standard deviation of diameters $\sigma(D)$ (the overlaid black line shows where $\left.\Delta_{\lambda} Z_{H}<0 \mathrm{~dB}\right)$.

and standard deviation. As expected, Gaussian PSDs with smaller standard deviations produce larger $\Delta_{\lambda} Z_{H}$ and $\Delta_{\lambda} Z_{\mathrm{DR}}$ magnitudes than the exponential or gamma PSDs. For example, the $\Delta_{\lambda} Z_{H}$ and $\Delta_{\lambda} Z_{\mathrm{DR}}$ values in Figs. $5 \mathrm{c}$ and $5 \mathrm{~d}$ range from -3.4 to $4.3 \mathrm{~dB}$ and from -5.5 to $2.4 \mathrm{~dB}$, respectively. These calculations use the parameterization for orientation angle distribution described above, whereas prescribing a narrower distribution of canting angles further increases the $\Delta_{\lambda} Z_{H}$ and $\Delta_{\lambda} Z_{\mathrm{DR}}$ magnitudes. As an example, setting $\sigma=8^{\circ}$ gives a range of $\Delta_{\lambda} Z_{H}$ from -4.8 to $5.9 \mathrm{~dB}$ and $\Delta_{\lambda} Z_{\mathrm{DR}}$ from -7.0 to $4.2 \mathrm{~dB}$.

In summary, the scattering calculations suggest that rain is unlikely to produce measurable dual-frequency signatures in $Z_{H}$ or $Z_{\mathrm{DR}}$, whereas hailstones can. These signatures are increased in magnitude with increasing liquid water fraction, suggesting they will be most prevalent below the melting layer and within wet growth regions of updrafts. In addition, the $\Delta_{\lambda} Z_{\mathrm{DR}}$ signatures should be more pronounced for more stabilized hydrometeor orientations and smaller axis ratios. Narrower particle size distributions and/or a smaller range of sizes are more favorable for observing the signatures. Broad PSDs within the radar sampling volume are expected to produce smaller $\Delta_{\lambda} Z_{H}$ and $\Delta_{\lambda} Z_{\mathrm{DR}}$, as many of the resonance peaks and dips get "washed out" upon averaging over the broad distribution.

\section{Observations}

Equipped with this theoretical understanding of the types of dual-frequency responses expected in rain and wet/melting hail, we now explore DOW7 observations from two cases in different regions: the first is of a convective storm in central Pennsylvania, and the second is from a severe (hail $\geq 2.5 \mathrm{~cm}$ observed) convective storm in Nebraska. A description of the radar, dataset, and data-processing steps is provided in section $3 a$, followed by an analysis of the measurements in section $3 \mathrm{~b}$.

\section{a. DOW datasets and quality assurance}

The dual-frequency radar data analyzed herein were collected with the DOW7 radar (the rest of its specifications are presented in Table 1). DOW7 operates at 9.35 and $9.50 \mathrm{~Hz}$, corresponding to wavelengths of approximately 3.209 and $3.158 \mathrm{~cm}$, respectively. The first dataset was collected in central Pennsylvania. The DOW7 radar visited The Pennsylvania State University (PSU) for two weeks in the autumn of 2014 as part of an 

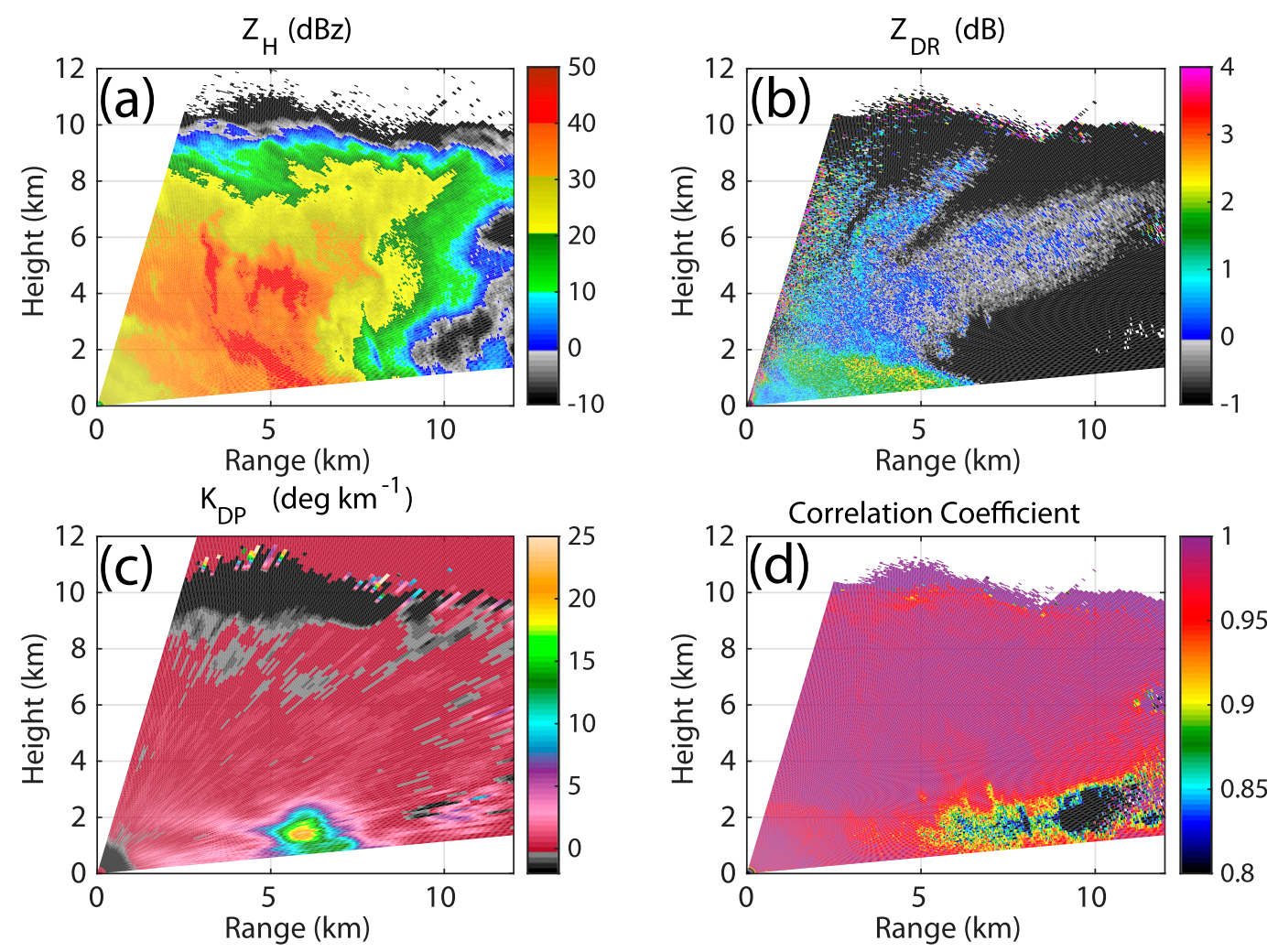

FIG. 6. Example RHI scan through a convective storm taken at 2157 UTC 30 Sep 2014. Fields shown are (a) reflectivity factor at horizontal polarization $Z_{H}(\mathrm{dBZ})$, (b) differential reflectivity $Z_{\mathrm{DR}}(\mathrm{dB})$, (c) specific differential phase $K_{\mathrm{DP}}\left({ }^{\circ} \mathrm{km}^{-1}\right)$, and (d) correlation coefficient $\rho_{\mathrm{hv}}$.

educational and outreach project called the Pennsylvania State University-Dual-Polarization Radar for Outreach and Precipitation Studies (PSU-DROPS; https:// www.eol.ucar.edu/system/files/edu_2014_PSUDROPS_ Summary.pdf). During its visit, students in the PSU radar meteorology and mesoscale meteorology classes collected observations over several intensive operations periods (IOPs). The students planned and executed the scanning strategies for all IOPs, which consisted of standard surveillance (PPI) scans, vertical cross sections, and near-zenith-pointing scans for $Z_{\mathrm{DR}}$ calibration purposes. DOW7 operated in a mode of simultaneous transmission and reception of horizontally $(\mathrm{H})$ and vertically (V) polarized waves during PSU-DROPS.

The first PSU-DROPS IOP took place on 30 September 2014. On this day, a weak cold front pushed through central Pennsylvania. This front was associated with a stalled, vertically stacked region of low pressure. Despite the relatively low CAPE available, the local National Weather Service Forecast Office anticipated a chance of small hail in any convective storms that might be initiated given the model-analyzed steep lapse rates (unfortunately, there are no operational soundings in central Pennsylvania). During IOP1, students collected observations from one of several marginally severe convective storms that passed through the region (Fig. 6). Local media quoted a National Weather Service employee who reported "dime sized" $(1.8 \mathrm{~cm})$ hail covering the ground in Bellefonte $(25 \mathrm{~km}$ northeast of the radar location) and Pleasant Gap (23 km northeast of the radar location). Unfortunately, the Bellefonte-Pleasant Gap storm was blocked by the radar truck's cab and was not well sampled during data collection. However, these reports and the NWS forecast that day suggest the environment was supportive of storms capable of producing small hail. Further, the storm analyzed herein contained very large values of specific differential phase $K_{\mathrm{DP}}$ at $\mathrm{X}$ band $\left(\sim 25^{\circ} \mathrm{km}^{-1}\right.$; Fig. $\left.6 \mathrm{c}\right)$, suggestive of large concentrations of small melting hail (e.g., Ryzhkov et al. 2013b; Kumjian and Lebo 2016).

Because our focus is on dual-frequency differences in $Z_{H}$ and $Z_{\mathrm{DR}}$, their relative calibration between frequencies is of most importance; $Z_{\mathrm{DR}}$ was calibrated using the frequent near-zenith-pointing scans collected during the IOPs. At vertical incidence with the antenna rotating through $360^{\circ}$, the average $Z_{\mathrm{DR}}$ is expected to be $0 \mathrm{~dB}$ in light rain because of raindrop azimuthal symmetry (e.g., Gorgucci et al. 1999; Bringi and 

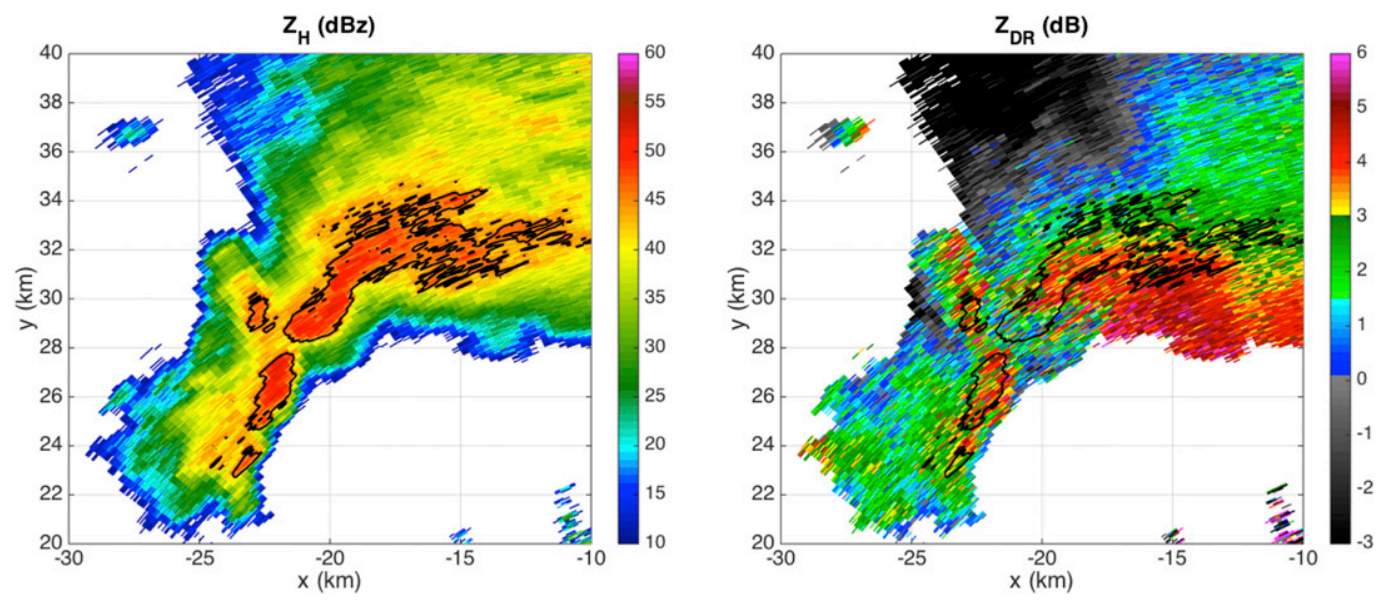

FIG. 7. Example $0.5^{\circ}$ PPI scan through a convective storm taken at 0240 UTC 17 Jun 2015 , roughly the time of a 2.5-cm hail report. Fields shown are (left) $Z_{H}(\mathrm{dBZ})$ and (right) $Z_{\mathrm{DR}}(\mathrm{dB})$. In both panels, the $45-\mathrm{dB} Z Z_{H}$ contour is overlaid.

Chandrasekar 2001). The median $Z_{\mathrm{DR}}$ in rain at vertical incidence was approximately $-0.4 \mathrm{~dB}$ for both the lowand high-frequency bands. These median offsets were added to the $Z_{\mathrm{DR}}$ values for the data shown herein. Next, the high- and low-frequency $Z_{H}$ were cross calibrated by comparing regions of light rain in the absence of noticeable attenuation, beam blockage, ground clutter, et cetera. Resonance scattering effects are not anticipated in light rain, as confirmed by the T-matrix calculations shown above. Light-rain points were selected with the following stringent criteria. First, gates with $15 \leq Z_{H} \leq 25 \mathrm{dBZ}$, copolar correlation coefficient $\rho_{\mathrm{hv}}>0.98$, and a beam height $<2 \mathrm{~km}$ were selected from each volume scan. These criteria isolate lighter precipitation echoes below the melting layer $(\sim 2 \mathrm{~km})$ that are most likely associated with rain. Next, in each scan we find the 5th-percentile value of differential phase $\Phi_{\mathrm{DP}}$ from these selected gates. We then select only the gates that have $\Phi_{\mathrm{DP}}$ within $10^{\circ}$ of this 5th-percentile value in an effort to avoid regions of the storm with large $\Phi_{\mathrm{DP}}$ accumulations, where biases from attenuation, differential attenuation, nonuniform beam filling, and antenna polarization errors are possible. The results were insensitive to selecting the 1st-percentile $\Phi_{\mathrm{DP}}$ value, so the 5 th percentile was used to include more data points in the analysis. We used $1 \mathrm{~h}$ of data for a total of $\sim 2.95 \times 10^{5}$ points. From these data, we found a median $Z_{H}$ offset of $2.03 \mathrm{~dB}$. This offset was added to the high-frequency data. Thus, we have high confidence that the $Z_{H}$ and $Z_{\mathrm{DR}}$ values at high and low frequencies are closely calibrated to each other. However, there is uncertainty in the absolute calibration of $Z_{H}$; thus, $Z_{H}$ data will be used for qualitative and illustrative purposes only.
The second dataset is from a storm sampled during IOP11 of PECAN (Geerts et al. 2017) on the evening of 16/17 June 2015. Early in the data collection, one of the more intense storms produced severe hail according to Storm Prediction Center hail reports (http://www.spc. noaa.gov/climo/reports/150616_rpts.html) of $\sim 2.5 \mathrm{~cm}$ at 0230 UTC and $\sim 3.8 \mathrm{~cm}$ at 0300 UTC. (Closer inspection reveals that the storm was over the location of the latter hail report at approximately 0240-0245 UTC; see Fig. 7.) As the system grew upscale, the maximum $Z_{H}$ values observed by DOW7 exceeded $45-50 \mathrm{~dB} Z$. The lowestelevation PPI scan from the closest WSR-88D instrument observed $Z_{H}>60 \mathrm{dBZ}$ of $\sim 2.5 \mathrm{~km}$ above the ground level (not shown), implying the continued presence of at least small hail in the storm. The PECAN data were calibrated in the same way as the PSU-DROPS data. Approximately $1 \mathrm{~h}$ of data $\left(\sim 1.53 \times 10^{5}\right.$ points $)$ were used. Offsets of -0.15 and $-0.14 \mathrm{~dB}$ were added to the high- and low-frequency $Z_{\mathrm{DR}}$ values, respectively, and the low-frequency $Z_{H}$ values were adjusted by $-0.32 \mathrm{~dB}$.

Radar observations are based on backscattering from a collection of particles in the sampling volume, which leads to statistical fluctuations of the received signal as these particles reshuffle their relative positions. Because of the finite number of samples used to estimate the moments, these estimates contain uncertainties. Expressions for these uncertainties can be derived, and depend on the number of samples (pulses), the Doppler spectral width, and the $\rho_{\text {hv }}$ (e.g., Bringi and Chandrasekar 2001; Melnikov 2004; Doviak and Zrnić 2006). Using such expressions and the hour of data from our PSU-DROPS analysis, we estimate the standard deviation of $Z_{H}$ to be between approximately 0.5 and $0.6 \mathrm{~dB}$ and the standard 
deviation of $Z_{\mathrm{DR}}$ to be between approximately 0.3 and $0.4 \mathrm{~dB}$. For the PECAN data, the standard deviations are somewhat higher: about $0.7-0.8 \mathrm{~dB}$ for $Z_{H}$ and $0.4-0.5$ for $Z_{\mathrm{DR}}$. These larger uncertainties for the PECAN case arise because of the faster scanning implemented.

Of particular interest for this study is an estimate of the uncertainties in the dual-frequency differences $\Delta_{\lambda} Z_{H}$ and $\Delta_{\lambda} Z_{\mathrm{DR}}$. Without the time series data, it is not possible to robustly characterize the covariances between the lowand high-frequency signals. However, we can estimate the uncertainties in $\Delta_{\lambda} Z_{H}$ and $\Delta_{\lambda} Z_{\mathrm{DR}}$ directly from observations of light rain, where we expect no dualfrequency differences, as discussed above. From the same data we used to perform the calibrations, we obtain standard deviations of $2.0 \mathrm{~dB}$ for $\Delta_{\lambda} Z_{H}$ and $0.4 \mathrm{~dB}$ for $\Delta_{\lambda} Z_{\mathrm{DR}}$ for PSU-DROPS and 2.3 and $0.7 \mathrm{~dB}$ for $\Delta_{\lambda} Z_{H}$ and $\Delta_{\lambda} Z_{\mathrm{DR}}$, respectively, for the PECAN case. These values will be used as uncertainty estimates in the following analysis.

The PSU-DROPS case includes RHI scans in which the radar collects data at high antenna elevation angles. For elevation angles of $>20^{\circ}-30^{\circ}$, hydrometeor polarimetric contrasts (in $Z_{\mathrm{DR}}$ and $K_{\mathrm{DP}}$ ) are diminished; this would tend to diminish the observed $\Delta_{\lambda} Z_{\mathrm{DR}}$ values as well. To account for this, we correct the $Z_{\mathrm{DR}}$ data as a function of antenna elevation angle following the approximate method of Ryzhkov et al. $(2005,2016)$ and Griffin et al. (2018). This approximation was tested against more rigorous treatments (Melnikov 2017) using the T-matrix calculations and performed extremely well for the particles considered in section 3 , and thus it is likely applicable here, too. Note that not many of these points are included in our analysis, so the results are insensitive to this correction. The data presented in Fig. $6 \mathrm{~b}$ have this correction applied.

As $\Phi_{\mathrm{DP}}$ accumulates along the radar wave's propagation path through precipitation, biases in $Z_{\mathrm{DR}}$ owing to antenna polarization errors can become noticeable. Hubbert et al. (2010a,b) found that, for radar systems with cross-polarization isolation of better than from -30 to $-35 \mathrm{~dB}$ (recent tests confirm the DOW radars meet or exceed this standard), the $Z_{\mathrm{DR}}$ bias owing to antenna polarization errors can increase to as much as $0.3 \mathrm{~dB}$ for up to $100^{\circ}$ of $\Phi_{\mathrm{DP}}$ accumulation. We would expect, then, that the worst-case antenna polarization errors will be manifested downrange of the heaviest precipitation core. This is also where one expects the worst biases from attenuation and differential attenuation.

For the PSU-DROPS case shown in Fig. 6, the maximum total $\Phi_{\mathrm{DP}}$ accumulation is about $100^{\circ}-110^{\circ}$ (not shown), suggesting a maximum of $\sim 0.3-\mathrm{dB}$ bias in $Z_{\mathrm{DR}}$ owing to antenna polarization errors. Within the regions of $Z_{H}>40 \mathrm{dBZ}$ used in the analysis, however, the maximum $\Phi_{\mathrm{DP}}$ accumulations are only on the order of $30^{\circ}-40^{\circ}$, which would produce antenna polarization errors in $Z_{\mathrm{DR}}$ of $\ll 0.3 \mathrm{~dB}$. In contrast, this $\Phi_{\mathrm{DP}}$ accumulation is likely associated with $\geq 1 \mathrm{~dB}$ of differential attenuation, assuming typical values of $A_{\mathrm{DP}} / K_{\mathrm{DP}}$ of $\sim 0.03-0.3 \mathrm{~dB}^{\circ-1}$ observed in heavy rain and melting hail (e.g., Hubbert et al. 2010a; Ryzhkov et al. 2013a). Thus, the effects of differential attenuation dwarf the effects of antenna polarization errors on $Z_{\mathrm{DR}}$. How do these biases affect the $\Delta_{\lambda} Z_{\mathrm{DR}}$ measurements? For antenna polarization errors, Hubbert et al. (2010a) find no wavelength dependence, besides the fact that $\Phi_{\mathrm{DP}}$ accumulates at a rate inversely proportional to the radar wavelength for hydrometeors small enough to be described by the Rayleigh approximation to scattering. Differences between the high- and low-frequency $\Phi_{\mathrm{DP}}$ accumulations were insignificant (within the fluctuations of the signals; not shown), even along the radials with the maximum $\Phi_{\mathrm{DP}}$ accumulation; thus, antenna polarization errors have a negligibly small impact on $\Delta_{\lambda} Z_{\mathrm{DR}}$. In contrast, our calculations from the previous section suggest maximum $\Delta_{\lambda} A_{\mathrm{DP}}$ values of $0.02 \mathrm{~dB} \mathrm{~km}^{-1}$ for large raindrops and small melting hailstones (with $1 \mathrm{~m}^{-3}$ concentration). Therefore, sufficiently large concentrations of such particles could lead to a positive $\Delta_{\lambda} Z_{\mathrm{DR}}$ bias that accumulates down the radial.

Now that the data have been quality controlled and the errors and uncertainties characterized, we analyze the data from both cases in section $3 \mathrm{~b}$ to explore any dual-X-bandfrequency hail signatures that are observed.

\section{b. Analysis}

\section{1) PSU-DROPS CASE}

Figure 8 shows the $\Delta_{\lambda} Z_{H}$ and $\Delta_{\lambda} Z_{\mathrm{DR}}$ fields from the same scan as Fig. 6. The nonzero $\Delta_{\lambda} Z_{H}$ and $\Delta_{\lambda} Z_{\mathrm{DR}}$ values within $2 \mathrm{~km}$ of the radar are thought to be associated with some combination of near-field antenna effects, and possibly melting snowflakes or graupel. These are not included in the subsequent analysis or statistics below. In contrast, there are notable regions of coherent $\Delta_{\lambda} Z_{H}<0$ (Fig. 8a) and $\Delta_{\lambda} Z_{\mathrm{DR}}>0$ (Fig. 8b) found in the range between 3 and $6 \mathrm{~km}$ and heights below about $6 \mathrm{~km}$ AGL. These regions are collocated with large $Z_{H}$ (cf. Fig. 6a) and therefore are candidates for regions of melting or wet hail. In addition, by assuming that Figs. 3-5 are realistic guides, we can infer that the backscattering in these regions is dominated by wet hail with sizes between approximately 17 and $20 \mathrm{~mm}$ (e.g., see Fig. 5d). Unfortunately, no hail reports are available from this storm for validation; however, recall that a nearby storm produced large amounts of dime-sized $(\sim 18 \mathrm{~mm})$ hail. The magnitude of the signature (especially in $\Delta_{\lambda} Z_{H}$ ) increases 

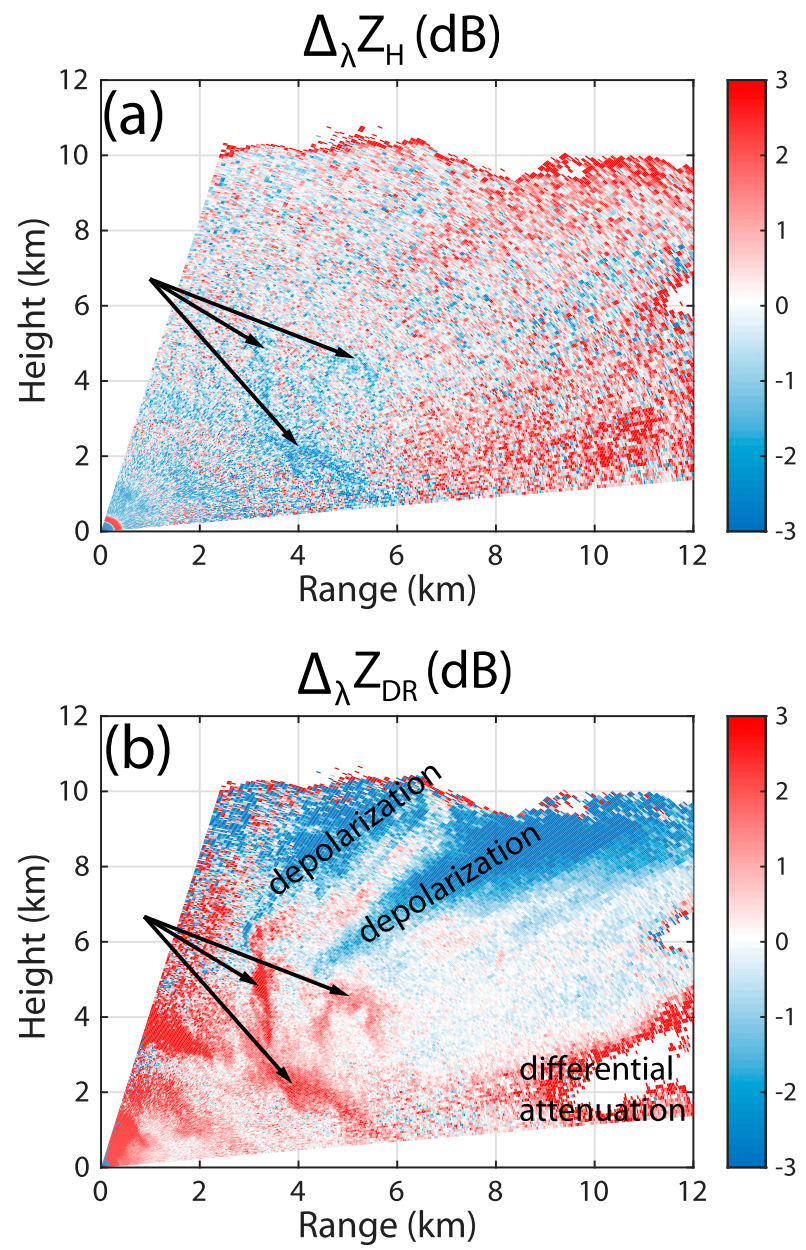

FIG. 8. As in Fig. 6, but for the dual-frequency differences (a) $\Delta_{\lambda} Z_{H}(\mathrm{~dB})$ and (b) $\Delta_{\lambda} Z_{\mathrm{DR}}(\mathrm{dB})$. Arrows indicate regions of inferred wet hail. Regions of depolarization and differential attenuation are also annotated in (b).

below about $2 \mathrm{~km}$, which is approximately the height of the melting layer. This enhancement of the dual-frequency signature below the melting layer is also consistent with expectations based on the scattering calculations presented in the previous section: as more liquid water accumulates on the particles, dual-frequency responses are amplified.

The $\Delta_{\lambda} Z_{H}$ magnitudes from approximately -1 to $-3 \mathrm{~dB}$ in the inferred hail regions are consistent with those computed in section 2 . However, $\Delta_{\lambda} Z_{\mathrm{DR}}$ magnitudes approaching $2 \mathrm{~dB}$ are larger than those computed above for a range of hailstone sizes. This discrepancy could arise from a number of factors, including the observed particles having smaller axis ratios and/or less wobbling than prescribed in our scattering calculations and/or shapes other than oblate spheroids (e.g., Jiang et al. 2018). Sensitivity tests (Figs. S1-S4 in the online supplemental material) suggest that reducing the standard deviation of the canting-angle distribution has a larger effect than reducing the axis ratio, and can increase the $\Delta_{\lambda} Z_{\mathrm{DR}}$ values in the $17-20-\mathrm{mm}$ size range such that they are closer to the observed values, especially for narrow PSDs.

Another notable dual-frequency feature that is evident is the radial swath of negative $\Delta_{\lambda} Z_{\mathrm{DR}}$ values above $6 \mathrm{~km}$ AGL, emanating from near the convective core (Fig. 8b). There is no similar signature in $\Delta_{\lambda} Z_{H}$. The radial orientation of the signature indicates it is related to propagation effects such as attenuation, differential attenuation, depolarization, et cetera. Referring to Fig. 6, we see evidence of depolarization streaks in $Z_{\mathrm{DR}}$ (e.g., Ryzhkov and Zrnić 2007; Kumjian 2013b), as well as regions of negative $K_{\mathrm{DP}}$ between 6 and $8 \mathrm{~km}$ AGL and between 3- and 6-km range that are suggestive of vertically aligned ice crystals in a strong electric field (e.g., Hubbert et al. 2014). Although depolarizationinduced biases in $Z_{\mathrm{DR}}$ are larger for smaller wavelengths (Ryzhkov and Zrnić 2007), the magnitude and sign of the resulting $Z_{\mathrm{DR}}$ streaks are also a function of the total differential phase shift $\Psi_{\mathrm{DP}}$, which includes the propagation differential phase shift $\Phi_{\mathrm{DP}}$ and the system differential phase shift. Closer investigation reveals that the system differential phase shift was considerably different for the two frequencies during this case, resulting in substantial differences in the total $\Psi_{\mathrm{DP}}$ at the location of depolarization. The resulting $Z_{\mathrm{DR}}$ streaks at the two frequencies are of opposite sign (i.e., the high-frequency $Z_{\mathrm{DR}}$ streaks are positive; not shown). Thus, rather than being associated with resonance scattering effects or differential attenuation, this dual-frequency signature in $\Delta_{\lambda} Z_{\mathrm{DR}}$ is caused by differences in the $Z_{\mathrm{DR}}$ depolarization streaks between the two frequencies.

Last, there is a radially oriented region of positive $\Delta_{\lambda} Z_{\mathrm{DR}}$ below about $4 \mathrm{~km}$ and beyond approximately $7-\mathrm{km}$ range. Again, propagation effects are the likely cause of this signature. Behind the heavy precipitation core, Fig. $6 \mathrm{~b}$ reveals a swath of negative $Z_{\mathrm{DR}}$ caused by differential attenuation, and Fig. $6 \mathrm{~d}$ features a swath of reduced $\rho_{\mathrm{hv}}$ resulting from nonuniform beam filling. Some combination of differential attenuation and nonuniform beam filling are responsible for this signature. Given the large $K_{\mathrm{DP}}$ observed, implying large concentrations of big raindrops and small melting hail, we favor differential attenuation as the explanation for this dual-frequency signature.

The dual-frequency signatures associated with wet and melting hail are found in numerous scans of this convective storm. To assess the bulk statistical characteristics of the dual-frequency hail signatures, we construct a joint distribution of $\Delta_{\lambda} Z_{H}$ and $\Delta_{\lambda} Z_{\mathrm{DR}}$ over a 1-h period from 2108 to 2208 UTC. Data were obtained from RHI scans of the storm, conditionally sampled such that only radar gates 
with $Z_{H} \geq 40 \mathrm{~dB} Z$ are used. This was done to isolate points associated with heavy rain and melting hail and to exclude regions of depolarization in ice aloft in the storm. Thus, these data should characterize the wet and melting-hail dual-frequency signatures. Figure 9 shows the resulting joint distribution. The green rectangular box centered on the origin represents the uncertainty in $\Delta_{\lambda} Z_{H}$ and $\Delta_{\lambda} Z_{\mathrm{DR}}$ values estimated from regions of rain, as described in the previous section. Statistical uncertainties in the signals alone without resonance scattering should generate a joint distribution with a symmetric pattern centered on the origin within the box. We have increased confidence that any points outside this box likely are from melting or wet hail. The distribution is clearly asymmetric about the origin; for example, it reveals points preferentially in the quadrant with $\Delta_{\lambda} Z_{H}<0 \mathrm{~dB}$ and $\Delta_{\lambda} Z_{\mathrm{DR}}>0 \mathrm{~dB}$, strongly suggesting a physical signal. From the T-matrix calculations above, this quadrant is consistent with the signal from liquid-coated oblate spheroids of sizes $\sim 17-20 \mathrm{~mm}$. Another region of interest is for $\Delta_{\lambda} Z_{H}>0 \mathrm{~dB}$ and $\Delta_{\lambda} Z_{\mathrm{DR}} \approx$ $0 \mathrm{~dB}$. The scattering calculations suggest these points could be from spherical or nonspherical wet hailstones with sizes of $<15 \mathrm{~mm}$ and/or sizes of $20-26 \mathrm{~mm}$. The former seems more likely in this case given its marginal nature and lack of any reports of severe hail at the surface.

The $\Delta_{\lambda} Z_{H}$ and $\Delta_{\lambda} Z_{\mathrm{DR}}$ pairs from the PSD calculations performed in section 2 , including the sensitivity tests, are overlaid in Fig. 9. The majority of these points fall within regions of the parameter space that frequently occur in the observations, suggesting general consistency between the calculations and observations. Where the calculations and observations are in agreement, it suggests that the observed particles dominating the backscattering are at least consistent with the simulated particles and their distribution of sizes. There is a noticeable region of disagreement in the bottom-left quadrant, where some simulated particles produce large negative $\Delta_{\lambda} Z_{H}$ and $\Delta_{\lambda} Z_{\mathrm{DR}}$ values not found in the observations. These come from horizontally oriented, melting stones in a very narrow size range $(\sim 15.7-16.7 \mathrm{~mm})$. Realistic hailstone size distributions and/or a larger degree of wobbling would tend to "smear" out these large negative values, possibly leading to the lack of observations in this part of the parameter space. In addition, this range of sizes is associated with normalized $Z_{H}$ values that are $10 \mathrm{~dB}$ less than surrounding sizes (Fig. 3a). Thus, given similar number concentrations to stones of adjacent sizes, particles in this size range contribute significantly less to the total backscattered power. The observations also show larger $\Delta_{\lambda} Z_{\mathrm{DR}}$ magnitudes than simulated. As mentioned above, sensitivity tests suggest that narrower cantingangle distributions and more oblate particles tend to have larger $\Delta_{\lambda} Z_{\mathrm{DR}}$ magnitudes; for example, the Gaussian

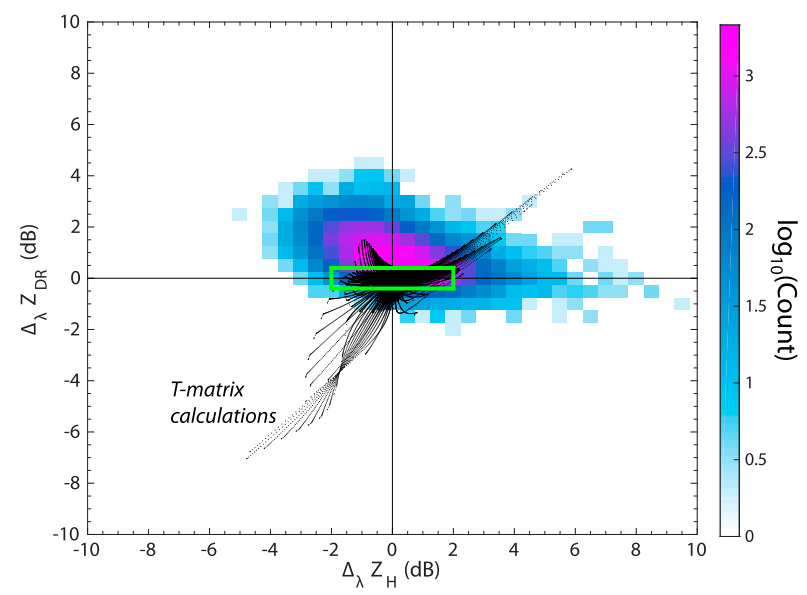

FIG. 9. Joint distribution of $\Delta_{\lambda} Z_{H}$ and $\Delta_{\lambda} Z_{\mathrm{DR}}$ (shading indicates base-10 logarithm of count within each bin) for the period 21082208 UTC 30 Sep 2014. Data were taken from RHI scans during this period, conditionally sampled such that only gates with $Z_{H} \geq$ $40 \mathrm{~dB} Z$ are included. The green box centered on the origin indicates the estimated uncertainties. Small black points are simulated values from PSDs using the T-matrix calculations for spheroids described in the text, including the sensitivity tests.

PSDs with $\sigma=8^{\circ}$ are the ones reaching farthest into the top-left quadrant of Fig. 9 and match the bulk of the observed data points, but not the extreme values farther out in the quadrant. The overall range of observed $\Delta_{\lambda} Z_{H}$ values is captured by the calculations, implying that the discrepancy is mainly a result of errors in our prescribed particle shapes, the distribution of liquid water on or within the particles, and/or their orientation distributions, all of which more substantially affect $Z_{\mathrm{DR}}$ and thus $\Delta_{\lambda} Z_{\mathrm{DR}}$ magnitudes.

Next, we compare the distribution of observations in the $\Delta_{\lambda} Z_{H}-\Delta_{\lambda} Z_{\mathrm{DR}}$ parameter space above and below the melting level, which was taken to be $2 \mathrm{~km}$ for this analysis. Recall that the scattering calculations suggest melting hailstones retaining the maximum allowable meltwater should lead to larger-magnitude signatures. The logarithm of the counts for each subset were normalized by the maximum value for that subset so that the two distributions can be compared. Figure 10 shows contours of $0.25,0.50$, and 0.75 normalized logarithmic counts for each distribution. In the bottom-left quadrant, $\left(\Delta_{\lambda} Z_{H}<0 \mathrm{~dB}\right.$ and $\left.\Delta_{\lambda} Z_{\mathrm{DR}}<0 \mathrm{~dB}\right)$ we see little difference in the distributions above and below the melting level, despite the scattering calculations showing such an expected increase in the magnitude of the signatures. This may come about for similar reasons to those described above: the band of sizes for this quadrant is extremely narrow and is located within a relative minimum in $Z_{H}$ relative to surrounding sizes. In contrast, larger differences can be seen in the other 


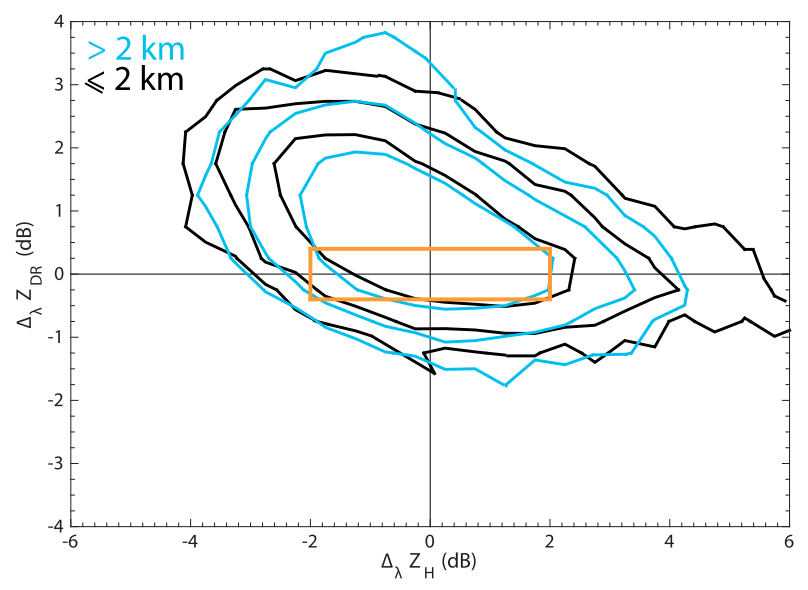

FIG. 10. Interquartile contours $(25 \%, 50 \%$, and $75 \%)$ of the normalized logarithmic joint distribution of $\Delta_{\lambda} Z_{H}$ and $\Delta_{\lambda} Z_{\mathrm{DR}}$ for the period 2108-2208 UTC 30 Sep 2014. Black contours are from below $2 \mathrm{~km}$ (approximate height of the melting level), and blue contours are from above $2 \mathrm{~km}$. The orange box overlaid shows the expected uncertainties.

quadrants. For example, the 0.75 (innermost) contour shows a nearly $\sim 0.5$-dB larger positive $\Delta_{\lambda} Z_{\mathrm{DR}}$ in the negative $\Delta_{\lambda} Z_{H}$ quadrant for the distribution below the melting level when compared with the one above. Similarly, there are larger positive $\Delta_{\lambda} Z_{H}$ values observed below the melting level. For particles with $\Delta_{\lambda} Z_{\mathrm{DR}}>$ $0.5 \mathrm{~dB}$, larger negative $\Delta_{\lambda} Z_{H}$ values are found as well. This suggests, in agreement with the scattering calculations, that wetter particles (i.e., melting hailstones) provide an amplified response relative to drier hailstones found above the melting level.

\section{PECAN CASE}

Figure 11 shows $\Delta_{\lambda} Z_{H}$ and $\Delta_{\lambda} Z_{\mathrm{DR}}$ from the same time as Fig. 7. As mentioned previously, the PECAN data are noisier, and thus a statistical analysis over a longer period of time may be more revealing. Similarly to the PSU-DROPS case, we compile the data over several volume scans and bin them to construct joint distributions in the $\Delta_{\lambda} Z_{H}-\Delta_{\lambda} Z_{\mathrm{DR}}$ parameter space. Data were selected if $Z_{H} \geq 45 \mathrm{~dB} Z$ and $\rho_{\mathrm{hv}} \geq 0.90$, from ranges of $>21 \mathrm{~km}$. The additional $\rho_{\mathrm{hv}}$ and range constraints were applied to help to eliminate data points that contain biological scatterers and ground clutter, which were numerous ahead of the storm. Although some ground clutter targets can produce large $\rho_{\mathrm{hv}}$ values, the fast scanning implemented in this case would tend to limit the occurrence of high- $\rho_{\mathrm{hv}}$ clutter points (Zrnić et al. 2006). Further, the $\rho_{\mathrm{hv}}$ constraint eliminates pixels associated with artifacts like nonuniform beam filling and three-body scattering. Additionally, manual checks of the data selected in the analysis of this case ensured that data from the convective storm (and not, e.g., ground clutter) were used. The results presented below are not qualitatively sensitive to changing the $Z_{H}$ threshold to $40 \mathrm{~dB} Z$.

The resulting distributions are shown for two time periods: one encompassing the 10 -min period near the time of the $2.5-\mathrm{cm}$ hail report, and one for a $30-\mathrm{min}$ period later on after upscale growth had begun (Fig. 12). The data exhibit a distribution of $\Delta_{\lambda} Z_{H}$ values ranging from approximately -4 to $8 \mathrm{~dB}$, which is much larger than the expected observational uncertainty (indicated by the blue box). Thus, this strongly suggests resonance scattering. The corresponding $\Delta_{\lambda} Z_{\mathrm{DR}}$ values are mainly within the range from -3 to $3 \mathrm{~dB}$. Interestingly, the distribution of data is skewed toward a different part of the parameter space than the PSU-DROPS case. In particular, far more data points are found in the $\Delta_{\lambda} Z_{H}>$ 0 quadrants-in particular, the $\Delta_{\lambda} Z_{H}>0$ and $\Delta_{\lambda} Z_{\mathrm{DR}}>0$ quadrant. This is true for the earlier time period (red contours in Fig. 12) when the storm was more intense and isolated, and evidently was producing larger hail. The scattering calculations suggest that wet/melting hail within the size range $\sim 20-27$ and/or $\sim 31-37 \mathrm{~mm}$ falls within these quadrants of the parameter space. These bands of sizes are consistent with the surface hail reports. The lack of points in the quadrant that dominated the PSU-DROPS case $\left(\Delta_{\lambda} Z_{H}<0\right.$ and $\left.\Delta_{\lambda} Z_{\mathrm{DR}}>0\right)$ suggests a relative lack of smaller melting hailstones, or at least a hail size distribution skewed toward larger stones that dominate the backscatter, in the PECAN case. Further, the lower $\Delta_{\lambda} Z_{\mathrm{DR}}$ values in the PECAN case in this quadrant could indicate comparatively fewer smaller stones with their maximum liquid water content, and/or more spherical stones overall. Clearly, however, improved surface observations of the hail size distributions and shapes are needed to better verify the inferences garnered from dual-frequency radar observations.

\section{Summary and discussion}

Two Doppler on Wheels radars were recently upgraded to transmit dual-polarized microwaves at closely spaced X-band frequencies. This allows for exploring the electromagnetic scattering response of various hydrometeors to incident radiation of two slightly different wavelengths. T-matrix scattering calculations were performed to determine the expected dual-frequency polarimetric signatures in rain and hail. These calculations show that, although rain is not expected to produce observable differences in the polarimetric variables between the two wavelengths, hail does. The signatures are especially pronounced for hail containing liquid 

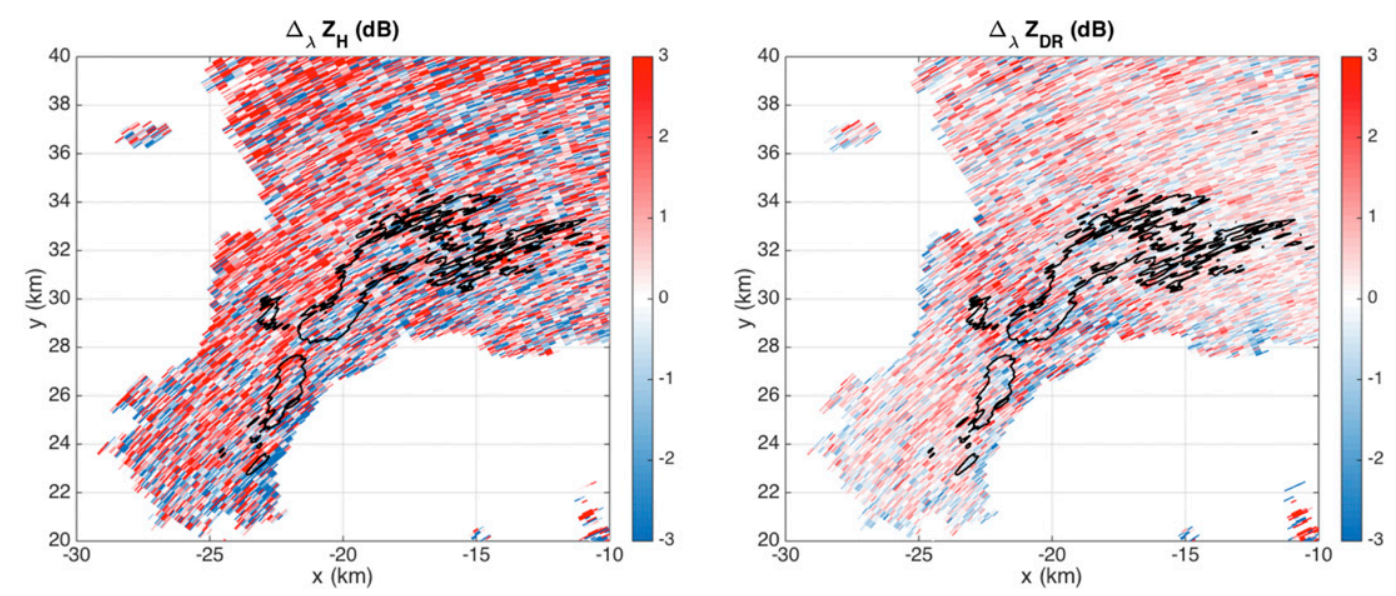

FIG. 11. As in Fig. 7, but (left) $\Delta_{\lambda} Z_{H}$ and (right) $\Delta_{\lambda} Z_{\mathrm{DR}}$.

water, as is possible during wet growth or melting. The different scattering response is a result of resonance scattering effects for electromagnetically large particles, wherein maxima and minima in the polarimetric radar variables occur at slightly different sizes for the two wavelengths. The T-matrix calculations suggest that differences between the two frequencies in the radar reflectivity factor at horizontal polarization $\Delta_{\lambda} Z_{H}$ and differential reflectivity $\Delta_{\lambda} Z_{\mathrm{DR}}$ can be positive or negative, with particular combinations occurring in narrow size bands. This is summarized qualitatively in Fig. 13. In the $\Delta_{\lambda} Z_{H}-\Delta_{\lambda} Z_{\mathrm{DR}}$ parameter space, each quadrant represents a unique combination of positive and/or negative dual-frequency differences. Sizes of melting hailstones $(\mathrm{mm})$ corresponding to each quadrant are indicated. Note that, as hail size increases, its location within the

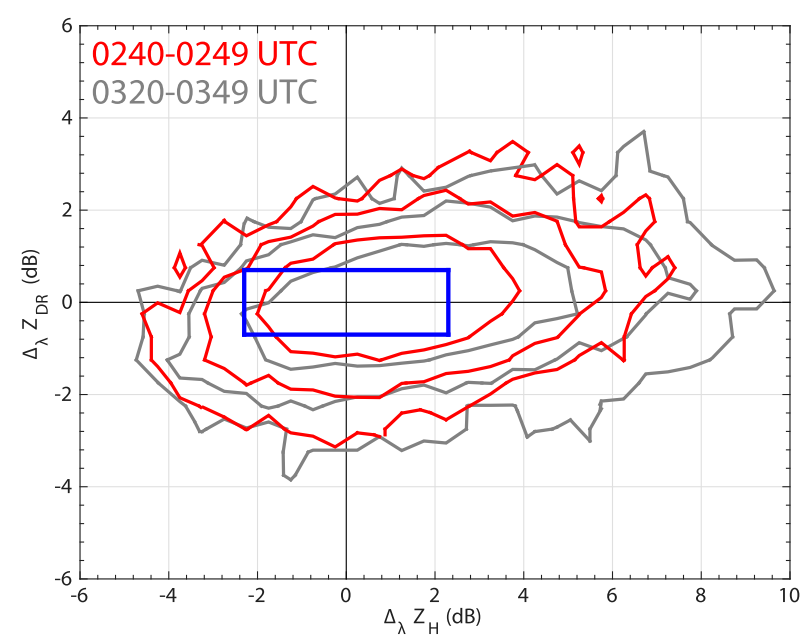

FIG. 12. Interquartile contours $(25 \%, 50 \%$, and $75 \%)$ of the normalized logarithmic joint distribution of $\Delta_{\lambda} Z_{H}$ and $\Delta_{\lambda} Z_{\mathrm{DR}}$ for the periods $0240-0249$ UTC (red) and 0320-0349 UTC (gray) on 17 Jun 2015. The blue box overlaid shows the expected uncertainties.
$\Delta_{\lambda} Z_{H}-\Delta_{\lambda} Z_{\mathrm{DR}}$ parameter space rotates clockwise ${ }^{1}$ around the four quadrants. Given this repeated pattern, the dualfrequency signatures identified herein likely will be more ambiguous in storms with a broad range of hail sizes.

A deep-convective storm bearing small hail in Pennsylvania and a severe storm bearing at least 2.5$3.8-\mathrm{cm}$ hail in Nebraska were both sampled using the dual-frequency, dual-polarization DOW7 radar. These data were used to explore the resonance scattering effects from microwave radiation at closely spaced X-band frequencies. Throughout the lifetime of these storms, repeated dual-frequency signatures were observed. According to the scattering calculations, these signatures are suggestive of wet and melting nonspherical hail in the size range $\sim 15-20 \mathrm{~mm}$ in the Pennsylvania case and $\sim 20-27$ and/or $\sim 31-37 \mathrm{~mm}$ in the Nebraska case. The Nebraska case did have $2.5-$ and $3.8-\mathrm{cm}$ hail reports during the period of data collection. For the Pennsylvania storm, although no ground validation was available, other storms in the area produced large amounts of dime-sized $(18 \mathrm{~mm})$ hail. In addition, extremely large $K_{\mathrm{DP}}$ measured in the Pennsylvania storm implies the presence of small melting hail.

The DOW7 radar observations analyzed herein were collected for other projects. The PSU-DROPS case was collected by students during the DOW7's brief visit to PSU as part of an education and outreach program. The Nebraska case data were collected during the PECAN field campaign. As such, the observations are limited to these individual cases, and scanning strategies were not optimized for our purposes here. More data should be collected and analyzed to assess the robustness of

\footnotetext{
${ }^{1}$ An exception to this is that the bottom-right quadrant is skipped when moving from 15.7 to $15.8-16.9 \mathrm{~mm}$.
} 


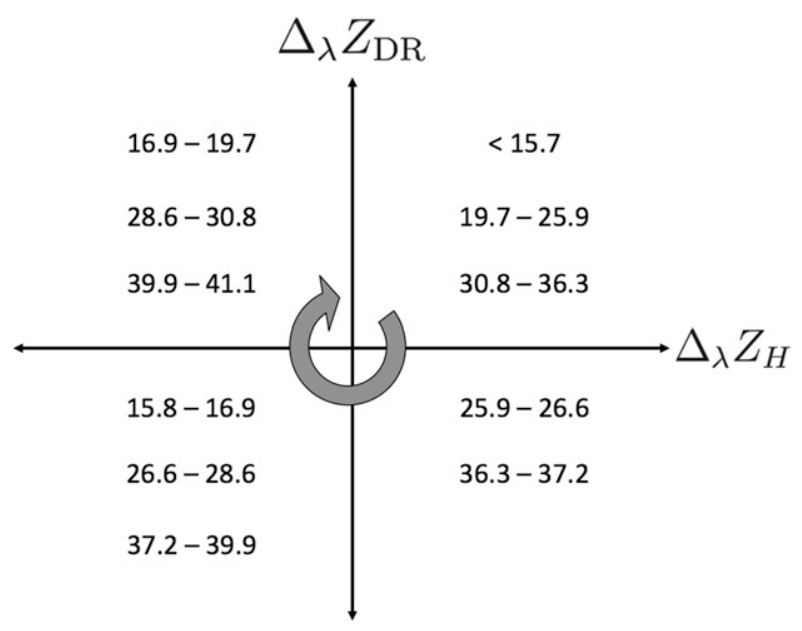

FIG. 13. Qualitative dual-frequency signature parameter space for differences in reflectivity factor at horizontal polarization $\Delta_{\lambda} Z_{H}$ vs differences in differential reflectivity $\Delta_{\lambda} Z_{\mathrm{DR}}$ for DOW7. The origin indicates $\Delta_{\lambda} Z_{H}=0 \mathrm{~dB}$ and $\Delta_{\lambda} Z_{\mathrm{DR}}=0 \mathrm{~dB}$. Numbers in each quadrant represent hail sizes $(\mathrm{mm})$, as based on T-matrix scattering calculations for melting oblate hailstones with maximum liquid water fraction. Numbers may be modified by $\pm 1 \mathrm{~mm}$ to account for the sensitivity tests. The gray arrow gives the sense of direction of the progression through the parameter space as hail size is increased. Note that $\Delta_{\lambda} Z_{H}$ and $\Delta_{\lambda} Z_{\mathrm{DR}}$ magnitudes are not implied by the locations of the numbers in each quadrant.

the dual-frequency approach described in this study, particularly in cases for which ground truth is available to better constrain hailstone shapes and sizes. Specifically, time series data in light rain should be analyzed to characterize the uncertainties in $\Delta_{\lambda} Z_{H}$ and $\Delta_{\lambda} Z_{\mathrm{DR}}$ more robustly. Further, hail size distributions with associated information about hailstone shapes are sorely needed. Future work should also embark on a more thorough exploration of the scattering properties of different hailstone shapes, densities, orientations, size distributions, and liquid water contents. Although this study focused mainly on $\Delta_{\lambda} Z_{H}$ and $\Delta_{\lambda} Z_{\mathrm{DR}}$, dual-frequency differences in specific differential phase $\Delta_{\lambda} K_{\mathrm{DP}}$, specific attenuation $\Delta_{\lambda} A_{H}$, and specific differential attenuation $\Delta_{\lambda} A_{\mathrm{DP}}$ should be explored, because these are dependent on hydrometeor concentration and could provide additional useful information.

In principle, the closely spaced dual-frequency approach can be applied at other frequencies, such as at S band as suggested by Melnikov et al. $(2010,2014)$. The main difference is that resonance scattering effects will occur for larger or smaller particles if the radar operating frequency is lower or higher, respectively. Therefore, the scattering calculations and interpretations thereof apply strictly to the dual-X-band frequencies of DOW7 and cannot be applied more broadly to other platforms. One may envision designing a closely spaced dual-frequency radar sensitive to specific hail sizes (e.g., "severe" or "significantly severe" hail as defined by operational weather services), or even a frequency-agile instrument that systematically adjusts one frequency while keeping the other fixed, thereby sampling different narrow ranges of hail sizes in an effort to probe the hail size distribution within a given storm.

The results herein should be seen as a preliminary step toward understanding the informative content of closely spaced dual-frequency signatures. An instrument like the DOW6 or DOW7 that operates at both frequencies using the same antenna provides the best platform for such observations, as the beams are better matched in space and time than different radars used in other studies (e.g., Melnikov et al. 2010, 2014). We suggest investigation of the dual-X-band signatures in other meteorological phenomena in which resonance scattering may be important, including the melting layer. Such observations could provide information on microphysical processes such as aggregation of melting particles within the melting layer (e.g., Trömel et al. 2013, 2014). A synthesis of closely spaced dual-frequency polarimetric radar observations, electromagnetic scattering calculations, and microphysical modeling may provide additional insights into the processes governing the formation, evolution, and distribution of electromagnetically large hydrometeors in precipitating systems.

Acknowledgments. The PSU-DROPS project was sponsored by an education and outreach grant from the National Science Foundation (NSF). Author MK is funded by NSF Award AGS-1661679 and by an award from the Insurance Institute for Business and Home Safety (IBHS). NSF support for the Center for Severe Weather Research comes from Grants AGS-1442054 and AGS1361237. The authors thank Dr. Marcus van Lier-Walqui (NASA GISS) for helpful comments. DOW7 datasets are available from CSWR. We also acknowledge the extremely thorough and constructive reviews by the reviewers, which substantially improved the study.

\section{APPENDIX}

\section{Melting-Hail Axis-Ratio Parameterization}

Here, we derive the new melting-hail axis-ratio parameterization used for the scattering calculations. Whereas previous treatments of melting hail assumed the same axis ratio $\gamma$ for both the liquid meltwater coating and the embedded ice core (e.g., Ryzhkov et al. 2013a), here we want to better simulate the possible "torus" of meltwater described by Rasmussen et al. (1984). Thus, we allow the overall particle axis ratio $\gamma$ to differ from the ice-core axis ratio $\gamma_{i}$ (cf. Fig. 1). 
The overall particle major and minor dimensions are given by $b=b_{i}+\delta b$ and $a=a_{i}+\delta a$, respectively, where the subscript $i$ indicates the ice core. Here, we assume $\delta a=0.5 \mathrm{~mm}$.

We can write the total particle volume $V=(\pi / 6) D^{3}$, where

$$
D=\left(a b^{2}\right)^{1 / 3}=\left[\left(a_{i}+\delta a\right)\left(b_{i}+\delta b\right)^{2}\right]^{1 / 3}
$$

is the equivalent volume spherical diameter of the particle. Similarly, the ice-core volume $V_{i}=(\pi / 6) D_{i}^{3}$, where

$$
D_{i}=\left(a_{i} b_{i}^{2}\right)^{1 / 3}
$$

is the equivalent volume spherical diameter of the ice core. Thus, the volume occupied by liquid meltwater is $V_{\text {liq }}=(\pi / 6)\left(D^{3}-D_{i}^{3}\right)$. Because we assume that the maximum liquid meltwater mass is retained on the particle as in Rasmussen and Heymsfield (1987) and Ryzhkov et al. (2013a), $\rho_{w} V_{\text {liq }}=m_{w, \max }$. From Eq. (1) in the text, it follows that

$$
\frac{\pi}{6} \rho_{w} D^{3}-\frac{\pi}{6} \rho_{w} D_{i}^{3}=m_{8}+0.139\left(\frac{\pi}{6} \rho_{\text {ice }} D_{i}^{3}\right) .
$$

Solving for the particle equivalent volume spherical diameter $D$ gives

$$
D^{3}=\frac{6 m_{8}}{\pi \rho_{w}}+D_{i}^{3} C
$$

where

$$
C=\left(1+0.139 \frac{\rho_{\text {ice }}}{\rho_{w}}\right)=1.1275 .
$$

Substituting Eqs. (A1) and (A2) yields

$$
\left[\left(a_{i}+\delta a\right)\left(b_{i}+\delta b\right)^{2}\right]=\frac{6 m_{8}}{\pi \rho_{w}}+C a_{i} b_{i}^{2} .
$$

Noting that $\gamma_{i} \equiv a_{i} / b_{i}$, we can substitute for $b_{i}$ and solve for $\delta b$, obtaining

$$
\delta b=\left[\left(\frac{6 m_{8}}{\pi \rho_{w}}+\frac{C a_{i}^{3}}{\gamma_{i}^{2}}\right) \frac{1}{a_{i}+\delta a}\right]^{\frac{1}{2}}-\frac{a_{i}}{\gamma_{i}} .
$$

\section{REFERENCES}

Atlas, D., and F. H. Ludlam, 1961: Multi-wavelength radar reflectivity of hailstorms. Quart. J. Roy. Meteor. Soc., 87, 523534, https://doi.org/10.1002/qj.49708737407.

Bodine, D. J., R. D. Palmer, and G. Zhang, 2014: Dual-wavelength polarimetric radar analyses of tornadic debris signatures. J. Appl. Meteor. Climatol., 53, 242-261, https://oi.org/10.1175/ JAMC-D-13-0189.1.
Bohren, C. F., 1992: On the absurdity and inadvisability of calling particles Mie scatterers. Opt. Photonics News, 3, 18-19.

- , and D. R. Huffman, 1983: Absorption and Scattering of Light by Small Particles. 1st ed. Wiley-VCH, $544 \mathrm{pp}$.

Borowska, L., A. V. Ryzhkov, D. S. Zrnić, C. Simmer, and R. Palmer, 2011: Attenuation and differential attenuation of 5-cm wavelength radiation in melting hail. J. Appl. Meteor. Climatol., 50, 59-76, https://doi.org/10.1175/2010JAMC2465.1.

Brandes, E. A., G. Zhang, and J. Vivekanandan, 2002: Experiments in rainfall estimation with a polarimetric radar in a subtropical environment. J. Appl. Meteor., 41, 674-685, https:// doi.org/10.1175/1520-0450(2002)041<0674:EIREWA >2.0.CO;2; Corrigendum. J. Appl. Meteor., 44, 186, https://doi.org/10.1175/ 1520-0450(2005)44<186:C >2.0.CO;2.

Bringi, V. N., and T. A. Seliga, 1977a: Scattering from axisymmetric dielectrics or perfect conductors imbedded in an axisymmetric dielectric. IEEE Trans. Antennas Propag., 25, 575-580, https:// doi.org/10.1109/TAP.1977.1141642.

— Ann. Telecommun., 32, 392-397.

— , and V. Chandrasekar, 2001: Polarimetric Doppler Weather Radar Principles and Applications. 1st ed. Cambridge University Press, $636 \mathrm{pp}$.

_ R. M. Rasmussen, and J. Vivekanandan, 1986: Multiparameter radar measurements in Colorado convective storms. Part II: Hail detection studies. J. Atmos. Sci., 43, 2564-2577, https:// doi.org/10.1175/1520-0469(1986)043<2564:MRMICC >2.0.CO;2.

Carbone, R., D. Atlas, P. Eccles, R. Fetter, and E. Mueller, 1973: Dual-wavelength radar hail detection. Bull. Amer. Meteor. Soc., 54, 921-924, https://doi.org/10.1175/1520-0477(1973)054<0921: DWRHD>2.0.CO;2.

Doviak, R. J., and D. S. Zrnić, 2006: Doppler Radar and Weather Observations. 2nd ed. Academic Press, 562 pp.

Eccles, P. J., and D. Atlas, 1973: A dual-wavelength radar hail detector. J. Appl. Meteor., 12, 847-854, https://doi.org/10.1175/ 1520-0450(1973)012<0847:ADWRHD>2.0.CO;2.

Ellis, S., and J. Vivekanandan, 2010: Water vapor estimates using simultaneous dual-wavelength radar observations. Radio Sci., 45, RS5002, https://doi.org/10.1029/2009RS004280.

Gaussiat, N., H. Sauvageot, and A. J. Illingworth, 2003: Cloud liquid water and ice content retrieved by multiwavelength radar. J. Atmos. Oceanic Technol., 20, 1264-1275, https://doi.org/ 10.1175/1520-0426(2003)020<1264:CLWAIC >2.0.CO;2.

Geerts, B., and Coauthors, 2017: The 2015 Plains Elevation Convection at Night field project. Bull. Amer. Meteror. Soc., 98, 767-786, https://doi.org/10.1175/BAMS-D-15-00257.1.

Gorgucci, E., G. Scarchilli, and V. Chandrasekar, 1999: A procedure to calibrate multiparameter weather radar using properties of the rain medium. IEEE Trans. Geosci. Remote Sens., 37, 269-276, https://doi.org/10.1109/36.739161.

Griffin, E. M., T. J. Schuur, and A. V. Ryzhkov, 2018: A polarimetric analysis of ice microphysical processes in snow, using quasi-vertical profiles. J. Appl. Meteor. Climatol., 57, 31-50, https://doi.org/10.1175/JAMC-D-17-0033.1.

Herzegh, P. H., and A. R. Jameson, 1992: Observing precipitation through dual-polarization radar measurements. Bull. Amer. Meteor. Soc., 73, 1365-1374, https://doi.org/10.1175/1520-0477(1992) 073<1365:OPTDPR $>2.0 . \mathrm{CO} ; 2$.

Hogan, R. J., N. Gaussian, and A. J. Illingworth, 2005: Stratocumulus liquid water content from dual-wavelength radar. J. Atmos. Oceanic Technol., 22, 1207-1218, https://doi.org/10.1175/JTECH1768.1.

Houser, J., H. B. Bluestein, and J. C. Snyder, 2015: Rapid-scan, polarimetric, Doppler radar observations of tornadogenesis 
and tornado dissipation in a tornado supercell: The "El Reno, Oklahoma" storm of 24 May 2011. Mon. Wea. Rev., 143, 26852710, https://doi.org/10.1175/MWR-D-14-00253.1.

Hubbert, J. C., S. M. Ellis, M. Dixon, and G. Meymaris, 2010a: Modeling, error analysis, and evaluation of dual-polarization variables obtained from simultaneous horizontal and vertical polarization transmit radar. Part I: Modeling and antenna errors. J. Atmos. Oceanic Technol., 27, 1583-1598, https://doi.org/ 10.1175/2010JTECHA1336.1.

,,,-- and $\longrightarrow, 2010 \mathrm{~b}$ : Modeling, error analysis, and evaluation of dual-polarization variables obtained from simultaneous horizontal and vertical polarization transmit radar. Part II: Experimental data. J. Atmos. Oceanic Technol., 27, 1599-1607, https://doi.org/10.1175/2010JTECHA1337.1.

- — - W.-Y. Chang, S. Rutledge, and M. Dixon, 2014: Modeling and interpretation of S-band ice crystal depolarization signatures from data obtained by simultaneously transmitting horizontally and vertically polarized fields. J. Appl. Meteor. Climatol., 53, 1659-1677, https://doi.org/10.1175/JAMC-D-130158.1.

Jameson, A. R., and R. Srivastava, 1978: Dual-wavelength Doppler radar observations of hail at vertical incidence. J. Appl. Meteor., 17, 1694-1703, https://doi.org/10.1175/1520-0450(1978)017<1694: DWDROO $>2.0 . \mathrm{CO} ; 2$.

— Colorado hailstorm. Part I: Dual-wavelength radar observations. J. Atmos. Sci., 37, 1763-1778, https://doi.org/10.1175/ 1520-0469(1980)037<1763:HGMIAC > 2.0.CO;2.

Jiang, Z., M. R. Kumjian, R. S. Schrom, I. Giammanco, T. BrownGiammanco, H. Estes, R. Maiden, and A. Heymsfield, 2018: Comparisons of electromagnetic scattering properties of real hailstones and spheroids. J. Appl. Meteor. Climatol., https:// doi.org/10.1175/JAMC-D-17-0344.1, in press.

Junyent, F., and V. Chandrasekar, 2016: An examination of precipitation using CSU-CHILL dual-wavelength, dual-polarization radar observations. J. Atmos. Oceanic Technol., 33, 313-329, https://doi.org/10.1175/JTECH-D-14-00229.1.

Kneifel, S., M. S. Kulie, and R. Bennartz, 2011: A triple-frequency approach to retrieve microphysical snowfall parameters. J. Geophys. Res., 116, D11203, https://doi.org/10.1029/2010JD015430.

_ A. von Lerber, J. Tiira, D. Moisseev, P. Kollias, and J. Leinonen, 2015: Observed relations between snowfall microphysics and triple-frequency radar measurements. J. Geophys. Res. Atmos., 120, 6034-6055, https://doi.org/10.1002/2015JD023156.

Kumjian, M. R., 2013a: Principles and applications of dualpolarization weather radar. Part I: Description of the polarimetric radar variables. J. Oper. Meteor., 1, 226-242, https://doi.org/ 10.15191/nwajom.2013.0119.

- 2013b: Principles and applications of dual-polarization weather radar. Part III: Artifacts. J. Oper. Meteor., 1, 265274, https://doi.org/10.15191/nwajom.2013.0121.

_ , and Z. J. Lebo, 2016: Large accumulations of small hail. 28th Conf. on Severe Local Storms, Portland, OR, Amer. Meteor. Soc., 8A.4, https://ams.confex.com/ams/28SLS/webprogram/ Paper301237.html.

— A. A. Ryzhkov, V. M. Melnikov, and T. J. Schuur, 2010: Rapid-scan super-resolution observations of a cyclic supercell with a dual-polarization WSR-88D. Mon. Wea. Rev., 138, 3762-3786, https://doi.org/10.1175/2010MWR3322.1.

Louf, V., O. Pujol, H. Sauvageot, and J. Riedi, 2014: The dualwavelength method for hailstorm detection by airborne radar. IEEE Trans. Geosci. Remote Sens., 52, 7327-7335, https://doi.org/ 10.1109/TGRS.2014.2311316.
Melnikov, V. M., 2004: Simultaneous transmission mode for the polarimetric WSR-88D: Statistical biases and standard deviations of polarimetric variables. NSSL Tech. Rep., 84 pp.

_ 2017: Parameters of cloud ice particles retrieved from radar data. J. Atmos. Oceanic Technol., 34, 717-728, https://doi.org/ 10.1175/JTECH-D-16-0123.1.

_, R. R. Lee, and N. J. Langlieb, 2010: Hail reflectivity signatures from two adjacent WSR-88Ds: Carrier frequency and calibration issues. 26th Conf. on Interactive Information and Processing Systems for Meteorology, Oceanography, and Hydrology, Atlanta, GA, Amer. Meteor. Soc., 8.5, https:// ams.confex.com/ams/90annual/webprogram/Paper161721.html.

— D. S. Zrnić, D. Burgess, and E. Mansell, 2014: Observations of hail cores of tornadic thunderstorms with three polarimetric radars. 30th Conf. on Environmental Information Processing Techniques, Atlanta, GA, Amer. Meteor. Soc., 11, https:// ams.confex.com/ams/94Annual/webprogram/Paper233038.html.

Meneghini, R., L. Liao, and L. Tian, 2005: A feasibility study for simultaneous estimates of water vapor and precipitation parameters using a three-frequency radar. J. Appl. Meteor., 44, 1511-1525, https://doi.org/10.1175/JAM2302.1.

Mie, G., 1908: Beiträge zur Optik trüber Medien, speziell kolloidaler Metallösungen (Contributions to the optics of cloudy media, especially colloidal metal solutions). Ann. Phys., 330, 377-445, https://doi.org/10.1002/andp.19083300302.

Mishchenko, M. I., 2000: Calculation of the amplitude matrix for a nonspherical particle in a fixed orientation. Appl. Opt., 39, 1026-1031, https://doi.org/10.1364/AO.39.001026.

Picca, J. C., and A. V. Ryzhkov, 2012: A dual-wavelength polarimetric analysis of the 16 May 2010 Oklahoma City extreme hailstorm. Mon. Wea. Rev., 140, 1385-1403, https://doi.org/ 10.1175/MWR-D-11-00112.1.

Rasmussen, R. M., and A. J. Heymsfield, 1987: Melting and shedding of graupel and hail. Part I: Model physics. J. Atmos. Sci., 44, 2754-2763, https://doi.org/10.1175/1520-0469(1987)044<2754: MASOGA $>2.0 . \mathrm{CO} ; 2$.

__, V. Levizzani, and H. R. Pruppacher, 1984: A wind tunnel and theoretical study on the melting behavior of atmospheric ice particles. III. Experiment and theory for spherical ice particles of radius $>500 \mu \mathrm{m}$. J. Atmos. Sci., 41, 381-388, https://doi.org/10.1175/1520-0469(1984)041<0381: AWTATS $>2.0 . \mathrm{CO} ; 2$.

Rinehart, R. E., and J. D. Tuttle, 1982: Antenna beam patterns and dualwavelength processing. J. Appl. Meteor., 21, 1865-1880, https:// doi.org/10.1175/1520-0450(1982)021<1865:ABPADW>2.0.CO;2.

Ryzhkov, A. V., and D. S. Zrnić, 2007: Depolarization in ice crystals and its effect on radar polarimetric measurements. J. Atmos. Oceanic Technol., 24, 1256-1267, https://doi.org/ 10.1175/JTECH2034.1.

- , T. J. Schuur, D. W. Burgess, P. L. Heinselman, S. E. Giangrande, and D. S. Zrnić, 2005: The Joint Polarization Experiment: Polarimetric rainfall measurements and hydrometeor classification. Bull. Amer. Meteor. Soc., 86, 809-824, https://doi.org/10.1175/BAMS-86-6-809.

— M. Pinsky, A. Pokrovsky, and A. Khain, 2011: Polarimetric radar observation operator for a cloud model with spectral microphysics. J. Appl. Meteor. Climatol., 50, 873-894, https:// doi.org/10.1175/2010JAMC2363.1.

— M. R. Kumjian, S. M. Ganson, and A. P. Khain, 2013a: Polarimetric radar characteristics of melting hail. Part I: Theoretical simulations using spectral microphysical modeling. J. Appl. Meteor. Climatol., 52, 2849-2870, https://doi.org/10.1175/ JAMC-D-13-073.1. 
and P. Zhang, 2013b: Polarimetric radar characteristics of melting hail. Part II: Practical implications. J. Appl. Meteor. Climatol., 52, 2871-2886, https://doi.org/10.1175/ JAMC-D-13-074.1.

_, P. Zhang, H. D. Reeves, M. R. Kumjian, T. Tschallener, S. Trömel, and C. Simmer, 2016: Quasi-vertical profiles-A new way to look at polarimetric radar data. J. Atmos. Oceanic Technol., 33, 551-562, https://doi.org/10.1175/JTECH-D-150020.1.

Snyder, J. C., H. B. Bluestein, G. Zhang, and S. J. Frasier, 2010: Attenuation correction and hydrometeor classification of high-resolution, X-band, dual-polarized mobile radar measurements in severe convective storms. J. Atmos. Oceanic Technol., 27, 1979-2001, https://doi.org/10.1175/2010JTECHA1356.1.

,,-- V. Venkatesh, and S. J. Frasier, 2013: Observations of polarimetric signatures in supercells by an X-band mobile Doppler radar. Mon. Wea. Rev., 141, 3-29, https://doi.org/ 10.1175/MWR-D-12-00068.1.

Tanamachi, R. L., and P. L. Heinselman, 2016: Rapid-scan polarimetric observations of central Oklahoma severe storms on 31 May 2013. Wea. Forecasting, 31, 19-42, https://doi.org/10.1175/ WAF-D-15-0111.1.

Tridon, F., A. Battaglia, and P. Kollias, 2013: Disentangling Mie and attenuation effects in rain using a $\mathrm{K}_{a}-\mathrm{W}$ dual-wavelength Doppler spectral ratio technique. Geophys. Res. Lett., 40, 5548-5552, https://doi.org/10.1002/2013GL057454.

, _ E. Luke, and P. Kollias, 2017: Rain retrieval from dualfrequency radar Doppler spectra: Validation and potential for a midlatitude precipitating case study. Quart. J. Roy. Meteor. Soc., 143, 1364-1380, https://doi.org/10.1002/qj.3010.

Trömel, S., M. R. Kumjian, A. V. Ryzhkov, C. Simmer, and M. Diederich, 2013: Backscatter differential phase-Estimation and variability. J. Appl. Meteor. Climatol., 52, 2529-2548, https://doi.org/10.1175/JAMC-D-13-0124.1.

, A. V. Ryzhkov, P. Zhang, and C. Simmer, 2014: Investigations of backscatter differential phase in the melting layer. J. Appl. Meteor. Climatol., 53, 2344-2359, https://doi.org/ 10.1175/JAMC-D-14-0050.1.

Tuttle, J. D., and R. E. Rinehart, 1983: Attenuation correction in dualwavelength analyses. J. Climate Appl. Meteor., 22, 1914-1921, https:// doi.org/10.1175/1520-0450(1983)022<1914:ACIDWA>2.0.CO;2.

_, V. N. Bringi, H. D. Orville, and F. J. Kopp, 1989: Multiparameter radar study of a microburst: Comparison with model results. J. Atmos. Sci., 46, 601-620, https://doi.org/10.1175/ 1520-0469(1989)046<0601:MRSOAM >2.0.CO;2.

Ulbrich, C. W., and D. Atlas, 1982: Hail parameter relations: A comprehensive digest. J. Appl. Meteor., 21, 22-43, https://doi.org/ 10.1175/1520-0450(1982)021<0022:HPRACD > 2.0.CO;2.

Vivekanandan, J., V. N. Bringi, and R. Raghavan, 1990: Multiparameter radar modeling and observations of melting ice. J. Atmos. Sci., 47, 549-564, https://doi.org/10.1175/1520-0469(1990)047<0549: MRMAOO $>2.0 . \mathrm{CO} ; 2$.

Williams, C. R., 2012: Vertical air motion retrieved from dualfrequency profiler observations. J. Atmos. Oceanic Technol., 29, 1471-1480, https://doi.org/10.1175/JTECH-D-11-00176.1.

Williams, J. K., and J. Vivekanandan, 2007: Sources of error in dual-wavelength radar remote sensing of cloud liquid water content. J. Atmos. Oceanic Technol., 24, 1317-1336, https:// doi.org/10.1175/JTECH2042.1.

Willis, P. T., 1984: Functional fits to some observed drop size distributions and parameterization of rain. J. Atmos. Sci., 41, 1648-1661, https://doi.org/10.1175/1520-0469(1984)041<1648: FFTSOD $>2.0 . \mathrm{CO} ; 2$.

Wurman, J., D. Dowell, Y. P. Richardson, P. M. Markowski, E. N. Rasmussen, D. W. Burgess, L. J. Wicker, and H. B. Bluestein, 2012: The Second Verification of the Origins of Rotation in Tornadoes Experiment: VORTEX2. Bull. Amer. Meteor. Soc., 93, 1147-1170, https://doi.org/10.1175/BAMS-D-11-00010.1.

Zrnić, D. S., V. M. Melnikov, and A. V. Ryzhkov, 2006: Correlation coefficients between horizontally and vertically polarized returns from ground clutter. J. Atmos. Oceanic Technol., 23, 381-394, https://doi.org/10.1175/JTECH1856.1. 